\title{
Trichinella britovi muscle larvae and adult worms: stage-specific and common antigens detected by two-dimensional gel electrophoresis-based immunoblotting
}

Sylwia Grzelak, Bożena Moskwa and Justyna Bień*

\begin{abstract}
Background: Trichinella britovi is the second most common species of Trichinella that may affect human health. As an early diagnosis of trichinellosis is crucial for effective treatment, it is important to identify sensitive, specific and common antigens of adult T. britovi worms and muscle larvae. The present study was undertaken to uncover the stage-specific and common proteins of $T$. britovi that may be used in specific diagnostics.

Methods: Somatic extracts obtained from two developmental stages, muscle larvae (ML) and adult worms (Ad), were separated using two-dimensional gel electrophoresis (2-DE) coupled with immunoblot analysis. The positivelyvisualized protein spots specific for each stage were identified through liquid chromatography-tandem mass spectrometry (LC-LC/MS).

Results: A total of 272 spots were detected in the proteome of T. britovi adult worms (Ad) and 261 in the muscle larvae (ML). The somatic extracts from Ad and ML were specifically recognized by T. britovi-infected swine sera at 10 days post infection (dpi) and $60 \mathrm{dpi}$, with a total of 70 prominent protein spots. According to immunoblotting patterns and LC-MS/MS results, the immunogenic spots recognized by different pig T. britovi-infected sera were divided into three groups for the two developmental stages: adult stage-specific proteins, muscle larvae stagespecific proteins, and proteins common to both stages. Forty-five Ad proteins (29 Ad-specific and 16 common) and thirteen ML proteins (nine ML-specific and four common) cross-reacted with sera at 10 dpi. Many of the proteins identified in Ad (myosin-4, myosin light chain kinase, paramyosin, intermediate filament protein B, actin-depolymerizing factor 1 and calreticulin) are involved in structural and motor activity. Among the most abundant proteins identified in ML were 14-3-3 protein zeta, actin-5C, ATP synthase subunit d, deoxyribonuclease-2alpha, poly-cysteine and histide-tailed protein, enolase, V-type proton ATPase catalytic and serine protease 30. Heat-shock protein, intermediate filament protein ifa- 1 and intermediate filament protein $B$ were identified in both proteomes.

Conclusions: To our knowledge, this study represents the first immunoproteomic identification of the antigenic proteins of adult worms and muscle larvae of T. britovi. Our results provide a valuable basis for the development of diagnostic methods. The identification of common components for the two developmental stages of $T$. britovi may be useful in the preparation of parasitic antigens in recombinant forms for diagnostic use.
\end{abstract}

Keywords: Trichinella britovi, Adult worm, Muscle larvae, 2-DE, Mass spectrometry, Immunoblotting

\footnotetext{
* Correspondence: jbien@twarda.pan.pl

Witold Stefański Institute of Parasitology, Polish Academy of Sciences, Twarda

51/55, 00-818 Warsaw, Poland
}

(c) The Author(s). 2018 Open Access This article is distributed under the terms of the Creative Commons Attribution 4.0 International License (http://creativecommons.org/licenses/by/4.0/), which permits unrestricted use, distribution, and 


\section{Background}

Trichinellosis is an important food-borne parasitic worldwide zoonosis caused by nematodes belonging to the genus Trichinella and is known to have high socioeconomic and medical significance. Humans typically acquire trichinellosis through the consumption of raw or improperly-processed meat of either farmed or wild animals containing infective muscle larvae (ML) of Trichinella [1-3]. The entire life-cycle of the parasite takes place in a single host. Trichinella displays three major antigenic stages: muscle larvae (ML), adult worms (Ad), and newborn larvae (NBL). Muscle larvae ingested with animal-derived meat are released into the host stomach upon the activation of digestive enzymes; they then migrate to the epithelial cells of the small intestine where they molt and transform into adult worms (Ad) within 48 hours post-infection (pi). Newborn larvae (NBL) are released after five days post-infection (dpi) and move through the lymphatic vessels to reach the striated muscle, where they grow and develop into encapsulated and non-encapsulated forms [4, 5]. All developmental stages of Trichinella elicit a protective immune response, as well as antigens which can be used for serological detection of Trichinella spp. infection. Several reports note that the Trichinella antigens produced by adult worms, new-born larvae and muscle larvae are stage-specific [6-8]. Our previous study indicated that together with stage-specific proteins, T. spiralis produces species-specific and common proteins for each developmental stage [9-11]. Although a few Trichinella antigens have been fully characterized, the complex interactions between the parasite and the host's immune system are not yet fully understood [12-16]. Thus, there is still a need to find other parasite proteins which may play an important role during the establishment of infection, which influence immune evasion strategies or modulate the host response. Recent studies have shown that a serine protease inhibitor released by $T$. spiralis may allow it to escape immune attack, and is related to the survival and colonization of the parasite in the hosts [17]. Identification of these proteins is not only important for understanding parasite-host interrelations, but is also a key factor in the development of serological diagnostic methods for species-specific differentiation and for detecting early-stage infection.

The combination of two-dimensional gel electrophoresis (2-DE) and mass spectrometry has been widely used to characterize the protein profiles of various Trichinella species $[9,18-21]$. When used together with immunoblotting, the techniques enable the identification of the proteins that induce immune response and which could be used for immunodiagnosis. This immunoproteomics tool has previously been used to determine both the characteristics of immunogenic proteins and the serological response directed against parasites, such as Schistosoma japonicum [22], Toxoplasma gondii [23], Ascaris lumbricoides [24] and Taenia solium [25]. As T. spiralis is considered the main etiological agent of most human infections and deaths, most studies have focused only on the identification of potentially immunogenic proteins expressed by $T$. spiralis stages [20, 26-29]. Although T. spiralis is commonly used as a representative species of the genus Trichinella, T. pseudospiralis, T. nativa and the T8 genotype, have also been described as being valuable sources of information regarding the parasite proteins needed for the development of immunological diagnostics $[18,19,30]$.

Over the years, numerous cases with trichinellosis have been attributed to T. britovi, considered the second-most common species of Trichinella and one that may affect human health [31-36]. Although the clinical and biological features observed during human infection caused by $T$. spiralis and T. britovi are different, it is not possible to attribute these features to a single species because the number of infective larvae is unknown. Trichinella spiralis infections are typically more severe than those caused by T. britovi, and the main distinctions between the two types of infections were that patients infected with $T$. spiralis displayed a longer duration of parasite-specific IgG, increased CPK levels, and a more severe intestinal symptomatology than those infected with $T$. britovi. This could be due to the fact that the fecundity of $T$. britovi females is lower than those of T. spiralis [36]. Our previous proteomic study of the excretory-secretory proteins of T. britovi muscle larvae found that the 5'-nucleotidase and serine protease may be potential proteins for diagnosis [9]. Currently, little is known about the protein profile shared by all developmental stages of $T$. britovi. Therefore, there is a need for more information about common and stage-specific $T$. britovi proteins to aid the development of species-specific diagnostics, and to better understand the adaptation of $T$. britovi to a parasitic niche and its host-parasite relationship.

The aim of the present study was to identify the $T$. britovi proteins that may be used in specific diagnostics. Somatic antigen extracts obtained from two developmental stages of $T$. britovi, muscle larvae (ML) and adult worms (Ad), were separated by two-dimensional gel electrophoresis (2-DE) coupled with immunoblot analysis. In addition, any positively-visualized proteins specific for each stage were further identified by liquid chromatography-tandem mass spectrometry (LC-LC/MS).

\section{Methods}

Experimental animals and collection of $T$. britovi adult worms and muscle larvae

The $T$. britovi nematodes had been maintained by several passages in male $\mathrm{C} 3 \mathrm{H}$ mice at the Institute of 
Parasitology, PAS. To generate ML and Ad forms of $T$. britovi, the mice were orally infected with a dose of 700 ML T. britovi. ML were collected 42 days post-infection (dpi), and Ad were collected at 4 dpi. Muscle larvae of $T$. britovi were recovered by $\mathrm{HCl}$-pepsin digestion from the previously-infected mice [37]. The recovered ML were subsequently purified several times with water through succeeding steps of sedimentation in cylinders. After the final sedimentation, the ML were collected into $1.5 \mathrm{ml}$ tubes. The larval pellet was extensively washed three times in phosphate-buffered saline (PBS) supplemented with antibiotics $(50 \mathrm{U} / \mathrm{ml}$ penicillin, $50 \mu \mathrm{g} / \mathrm{ml}$ streptomycin). The adult worms were collected from the small intestine of $\mathrm{C} 3 \mathrm{H}$ mice (3-4 months-old). Briefly, after recovery, the intestines were washed with sterile water with the use of a syringe, cut longitudinally and crosswise into 1-2 $\mathrm{cm}$ pieces, placed on a mesh in a conical dish filled with RPMI 1640 medium (Sigma-Aldrich Chemie $\mathrm{GmbH}$, Steinheim, Germany) supplemented with $25 \mathrm{mM}$ HEPES, $2 \mathrm{mM}$ L-glutamine, antibiotics $(50 \mathrm{U} / \mathrm{ml}$ penicillin, $50 \mu \mathrm{g} / \mathrm{ml}$ streptomycin) and incubated for three hours at $37^{\circ} \mathrm{C}$. Any Ad worms located on the bottom of the dish were then collected into $15 \mathrm{ml}$ tubes, and washed three times with PBS supplemented with antibiotics. The $T$. britovi stages were then stored at $-70{ }^{\circ} \mathrm{C}$ before protein extraction and proteomic analysis.

\section{Protein extraction}

The same protein sample preparation procedure was used for both T. britovi stages. After thawing, the collected T. britovi ML and Ad were again extensively washed three times in PBS and then suspended in a lysis buffer (8 M Urea, 4\% CHAPS, $40 \mathrm{mM}$ Trizma base), supplemented with protease inhibitor cocktail (Roche, Berlin, Germany). The protein extract was then homogenized in glass Potter-homogenizer and disintegrated by sonication three times for $10 \mathrm{~s}$. The lysis extract was clarified by centrifugation at $14,000 \times$ $g$ at $4{ }^{\circ} \mathrm{C}$ for $15 \mathrm{~min}$. The supernatant was collected, placed in new $1.5 \mathrm{ml}$ tubes, and protein concentration was measured with the use of a NanoDrop-1000 Uv/ Vis Spectrometer (NanoDrop Technologies, Wilmington, USA). The proteins were frozen at $-70{ }^{\circ} \mathrm{C}$ for further analysis.

\section{Two dimensional gel electrophoresis (2-DE)}

Three replicates of $T$. britovi protein samples were run in parallel on three immobilized $\mathrm{pH}$-gradient IPG strips (RioRad, Hercules, USA). The $100 \mu \mathrm{g}$ samples of previously prepared protein extracts from $T$. britovi Ad and ML were purified with the 2-D Clean-Up Kit (GE Healthcare, New Jersay ,USA) in accordance with the manufacturer's protocol. After the final centrifugation step, the protein pellets were rehydrated overnight in $250 \mu \mathrm{l}$ of 2-D Starter Kit Rehydration/Sample Buffer (BioRad, Hercules, USA) and loaded onto a $7 \mathrm{~cm} \mathrm{pH}$ 3-10 IPG strips (BioRad, Hercules, USA) for first dimension separation. The protein samples were separated in accordance with their $\mathrm{pI}$ values through isoelectric focusing (IEF) using a Protean IEF Cell (BioRad) device at $20{ }^{\circ} \mathrm{C}$ as follows: first step $15 \mathrm{~min}$ at $250 \mathrm{~V}$; second step rapid ramping to $4000 \mathrm{~V}$ for two hours; and third step for 15,500 Vhrs (current limit of $50 \mu \mathrm{A} / \mathrm{IPG}$ strip). After focusing, the strips were submitted for two steps of equilibration, the first for 25 min in ReadyPrep 2-D starter Kit Equilibration Buffer I, containing DTT (BioRad, USA), and the second for 25 min in ReadyPrep 2-D Starter Kit Equilibration Buffer II containing iodoacetamide (BioRad, USA) instead of DTT. The two-dimensional SDS-PAGE was run using $12 \%$ acrylamide separating gels and $4 \%$ polyacrylamide stacking gels in a Mini-PROTEAN Tetra Cell electrophoresis chamber (BioRad, USA) at $200 \mathrm{~V}$ for approximately $50 \mathrm{~min}$. The PageRuler Unstained Protein Ladder (Thermo Fisher Scientific, Massachusetts, USA) was loaded onto each gel as a weight marker. All gels were separated in the same conditions.

\section{Silver staining and 2-DE immunoblotting}

After 2-DE electrophoresis gels were silver-stained using PlusOne Silver Staining Kit (GE Healthcare) in accordance with manufacturer's protocol, while those used for 2-DE immunoblotting were not stained. The obtained gels were scanned with ChemiDoc MP system (BioRad, USA) and analyzed in Image Lab 5.2.1. software (BioRad, USA).

In addition, proteins from unstained gels were transferred onto Immuno-Blot polyvinylidene fluoride (PVDF) membranes (BioRad) by a wet transfer system (BioRad, USA) at $95 \mathrm{~V}$ for one hour in cool conditions. The PVDF membranes with the Ad and ML proteins were blocked in Pierce Protein-Free T20 (TBS) Blocking Buffer (Thermo Fisher Scientific) for one hour at room temperature. Following this, the PVDF membranes were incubated overnight at $4{ }^{\circ} \mathrm{C}$ with $T$. brito$v i$-infected pig sera (dose of 20,000 ML) diluted 1:100, at $10 \mathrm{dpi}$ and $60 \mathrm{dpi}$. Adult worm proteins transferred onto the membrane were treated with antisera taken at $10 \mathrm{dpi}$ while the ML proteins were treated with antisera from $10 \mathrm{dpi}$ and $60 \mathrm{dpi}$. The secondary antibody HRP-conjugated goat anti-pig IgG were diluted 1:35 000 (Sigma-Aldrich, Louis, USA). The uninfected sera were used as parallel negative controls. The negative control experiment used the same method as mentioned above. The immunoreactive proteins were visualized on a film using a Super Signal West Pico Chemiluminescent Substrate (Thermo Fisher Scientific, 
Walthman, USA) according to the provided instruction. Reproducibility of the immune recognition was verified by repeating the immunoblot at least three times.

\section{LC-MS/MS}

Spots of interest visible on the films were gently excised from compatible silver-stained gels and analyzed by liquid chromatography coupled to a mass spectrometer in the Laboratory of Mass Spectrometry, Institute of Biochemistry and Biophysics, Polish Academy of Sciences (Warsaw, Poland). Samples were concentrated and desalted on a RP-C18 pre-column (Waters), and further peptide separation was achieved on a nano-Ultra Performance Liquid Chromatography (UPLC) RP-C18 column (Waters, BEH130 C18 column, $75 \mu \mathrm{m}$ i.d., $250 \mathrm{~mm}$ long) in a nanoACQUITY UPLC system, using a 45 minute linear acetonitrile gradient. The column outlet was directly coupled to an Electrospray ionization (ESI) ion source of a Orbitrap Velos type mass spectrometer (Thermo Scientific, Waltham, USA), operating in a regime of a data-dependent MS to MS/MS switch with HCD-type peptide fragmentation. An electrospray voltage of 1.5 $\mathrm{kV}$ was used.

\section{Bioinformatics}

Raw data files were pre-processed with Mascot Distiller software (version 2.4.2.0, MatrixScience). The obtained peptide masses and fragmentation spectra were matched to the National Center Biotechnology Information (NCBI) non-redundant database $(115,488,495$ sequences/ 42,334,050,411 residues), with a Nematoda filter (748,652 sequences) using the Mascot search engine (Mascot Daemon v. 2.4.0, Mascot Server v. 2.4.1, MatrixScience). The following search parameters were applied: enzyme specificity was set to trypsin, peptide mass tolerance to $\pm 30 \mathrm{ppm}$ and fragment mass tolerance to $\pm 0.1 \mathrm{Da}$. The protein mass was left as unrestricted, and mass values as monoisotopic, with one missed cleavage being allowed. Alkylation of cysteine by carbamidomethylation as fixed, oxidation of methionine was set as a variable modification. Protein identification was performed using the Mascot search engine (MatrixScience), with a probability-based algorithm. The expected value threshold of 0.05 was used for the analysis, which means that all peptide identifications had less than a one-in-20 chance of being a random match. All proteins identified in the MASCOT search were subsequently assigned to the UniProtKB database (https://www.uniprot.org/) and QuickGO (http:// www.ebi.ac.uk/QuickGO/) and classified in gene ontology (GO) in accordance with its molecular function, biological process and cellular component information.

\section{Results}

\section{2-DE and immunoblot analysis of Ad and ML proteins of} T. britovi

To identify species-specific parasite antigens, extracts of T. britovi Ad and ML were separated by IEF on $7 \mathrm{~cm}, \mathrm{pH}$ 3-10 strips. Figures 1a and 2a represent one of the three replicated silver-stained proteome gels used for further analysis. The proteomes of Ad and ML presented 261 and 272 spots, respectively, with a $\mathrm{pH}$ range of 3-10 and molecular weight (MW) ranging from $10 \mathrm{kDa}$ to $250 \mathrm{kDa}$ (Figs. 1a, 2a). The results of the 2-DE immunoblot of the Ad and ML extracts are given in Figs. $1 b$ and 2b, c. Approximately 31 Ad-immunoreactive protein spots and nine ML protein spots were positively recognized by $T$. britovi-infected swine sera at $10 \mathrm{dpi}$. Sera taken from pigs at $60 \mathrm{dpi}$ recognized $30 \mathrm{ML}$ protein spots. Potentially immunogenic proteins migrated with a MW between 10 and $150 \mathrm{kDa}$ (Figs. 1b, 2b, c). These immunoreactive spots matched to the corresponding protein spots on silver stained gels, and were selected for further LC-MS/MS identification. No protein reacted to uninfected swine sera (Figs. 1c, 2d).

\section{LC-MS/MS analysis of antigenic proteins of $T$. britovi specific for adult worms}

The protein data obtained in the present study were compared against deposited protein sequences available for other Trichinella spp. The obtained MS/MS datasets were therefore searched against the NCBI database with the Mascot search engine, and the samples detected as Trichinella spp.-specific were selected based on score, matches and sequence coverage data. Thirty-one of the positive spots recognized by the $T$. britovi-infected serum samples taken at $10 \mathrm{dpi}$ were matched and located on the silver-stained gels and then subjected to LC-MS/MS analysis (Table 1). The results revealed the presence of 45 proteins with potential antigenic character, among which 29 were specific only for the adult stage of $T$. britovi. Five of these antigenic proteins were present in more than one spot (Table 2 ), and most of the analyzed spots contained more than one protein. The highest number of proteins were identified from spot number 22, containing five proteins, spots 6,7 and 19 containing four proteins, and spots $8,23,28,30$ and 31 containing three proteins (Table 1). Only one protein was present in nine spots (nos 2, 4, 11, 12, 13, 14, 24, 25 and 29). No protein set was found in spot no. 21. Several of the immunogenic proteins specific for adult worms were matched to myosin, actin-depolymerizing factor 1 , isoforms $\mathrm{a} / \mathrm{b}$, heat-shock cognate $71 \mathrm{kDa}$ protein, stress-70 protein, Rho GDP-dissociation inhibitor 1, paramyosin or serine/arginine-rich splicing factor 1 (Tables 1 and 2). 


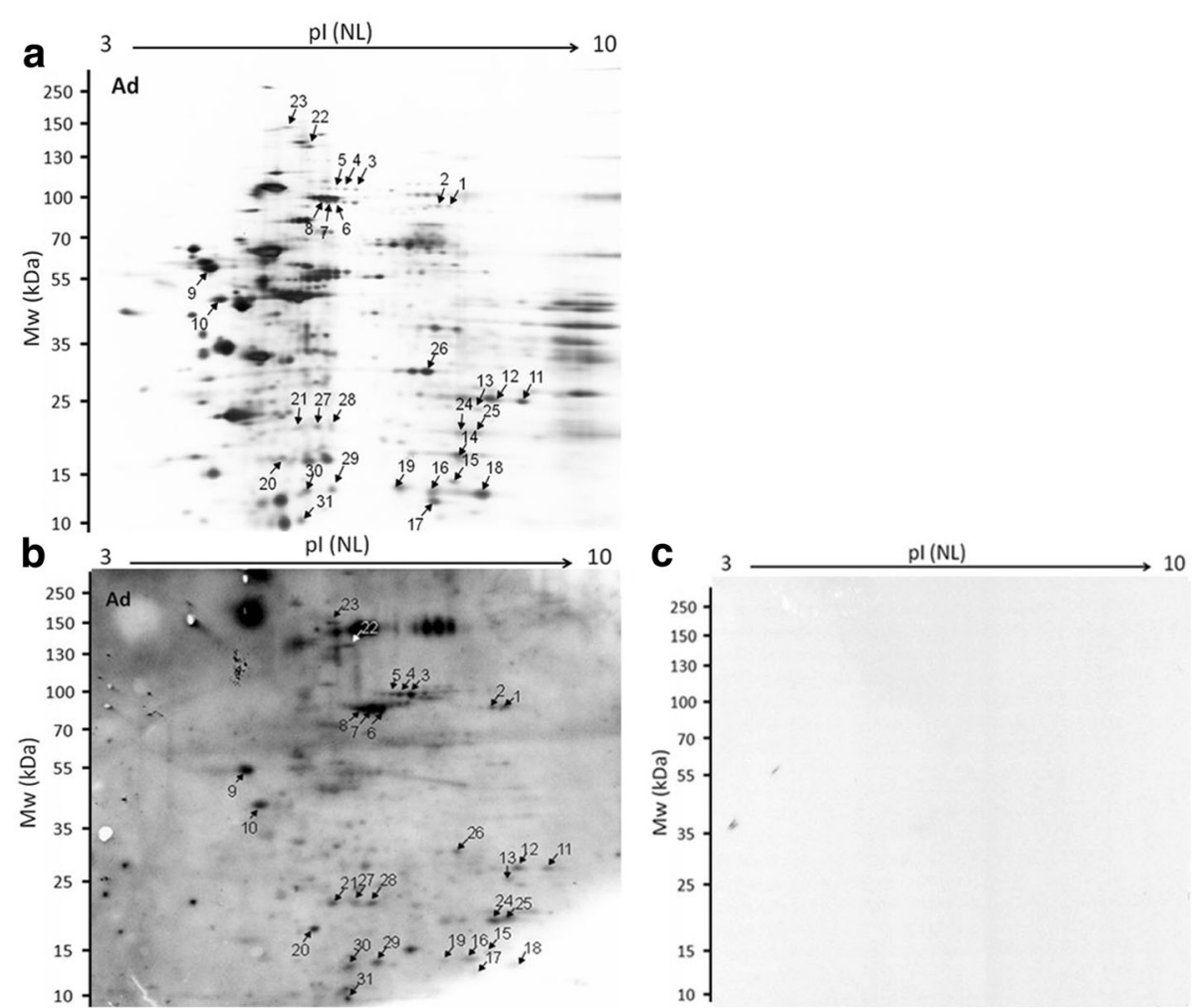

Fig. 1 An image of 2-DE separations and immunoblot analysis of somatic antigen extract of T. britovi adult worms (Ad). a 2-DE gels were stained with a silver stain. $\mathbf{b}$ 2D-immunoblot of Ad proteins were probed with infected pig sera at $10 \mathrm{dpi}$. c 2D-immunoblot of Ad proteins probed with uninfected swine sera. Matched spots selected for subsequent LC-MS/MS analysis are marked

\section{LC-MS/MS analysis of antigenic proteins of $T$. britovi specific for muscle larvae}

Nine ML protein spots cross-reacting with T. britovi infected swine sera were identified by MS analysis at 10 $\mathrm{dpi}$, and 30 spots were found at $60 \mathrm{dpi}$ (Tables 3 and 4).

LC-MS/MS analysis revealed the presence of $13 \mathrm{immu}-$ noreactive ML proteins recognized by sera at $10 \mathrm{dpi}$ samples, nine of which were stage-specific (Table 5). In the samples at $60 \mathrm{dpi}, 39$ proteins were recognized by sera, with only 25 being stage-specific (Table 6). One protein recognized by sera at 10 dpi was present in two spots (nos 29,30 ) (Table 5) and seven proteins recognized by sera at 60 dpi were present in more than one spot (Table 6). The highest number of proteins, i.e. seven, were observed in spot number 30, followed by four proteins in spots 17 and 29 , and three proteins in spots 4, 6, 12, 20, 30 and 32 (Table 4 ). The remaining spots contained fewer than three proteins (Tables 3 and 4). Only spot no 34 contained no proteins recognized by sera at $10 \mathrm{dpi}$, while at $60 \mathrm{dpi}$, three spots contained no recognized proteins (7, 8 and 28$)$ (Tables 3 and 4).

The following immunogenic proteins specific for the ML stage were identified in the $10 \mathrm{dpi}$ serum samples: $26 \mathrm{~S}$ protease regulatory subunit 7; actin-5C; enolase; protein disulfide-isomerase 2; V-type proton ATPase catalytic subunit $\mathrm{A}$; and serine protease 30 (Table 5 ). The following were identified in the 60 dpi samples: 14-3-3 protein zeta; $40 \mathrm{~S}$ ribosomal protein SA; calponin-like protein OV9M; propionyl-CoA carboxylase alpha chain; Rab GDP dissociation inhibitor alpha; secernin-3; serine protease 30; Toll-interacting protein (Table 6). Finally, the following proteins were identified in both the 10 and $60 \mathrm{dpi}$ samples: actin $5 \mathrm{C}$; serine protease; intermediate filament protein (IFA-1); and mitochondrial-processing peptides subunit beta (Tables 5 and 6).

\section{LC-MS/MS analysis of antigenic proteins common for both stages of $T$. britovi}

Although some proteins were found to be specific for both the Ad and ML stages of T. britovi, most were common to both stages (Table 7). The following proteins appeared in both proteomes, and were most frequently identified from multiple spots: heat-shock protein beta-1 (present in five spots - Ad $10 \mathrm{dpi}$, four spots - ML $60 \mathrm{dpi}$ ); intermediate filament protein IFA-1; partial (present in five spots - Ad $10 \mathrm{dpi}$, three spots - ML $60 \mathrm{dpi}$, four spots - ML $10 \mathrm{dpi}$ ); intermediate filament protein IFA-1 (present in five spots - Ad $10 \mathrm{dpi}$, three spots - $10 \mathrm{dpi}$ and one spot - ML $60 \mathrm{dpi}$; peroxiredoxin-2/partial (present in three spots - Ad 10 


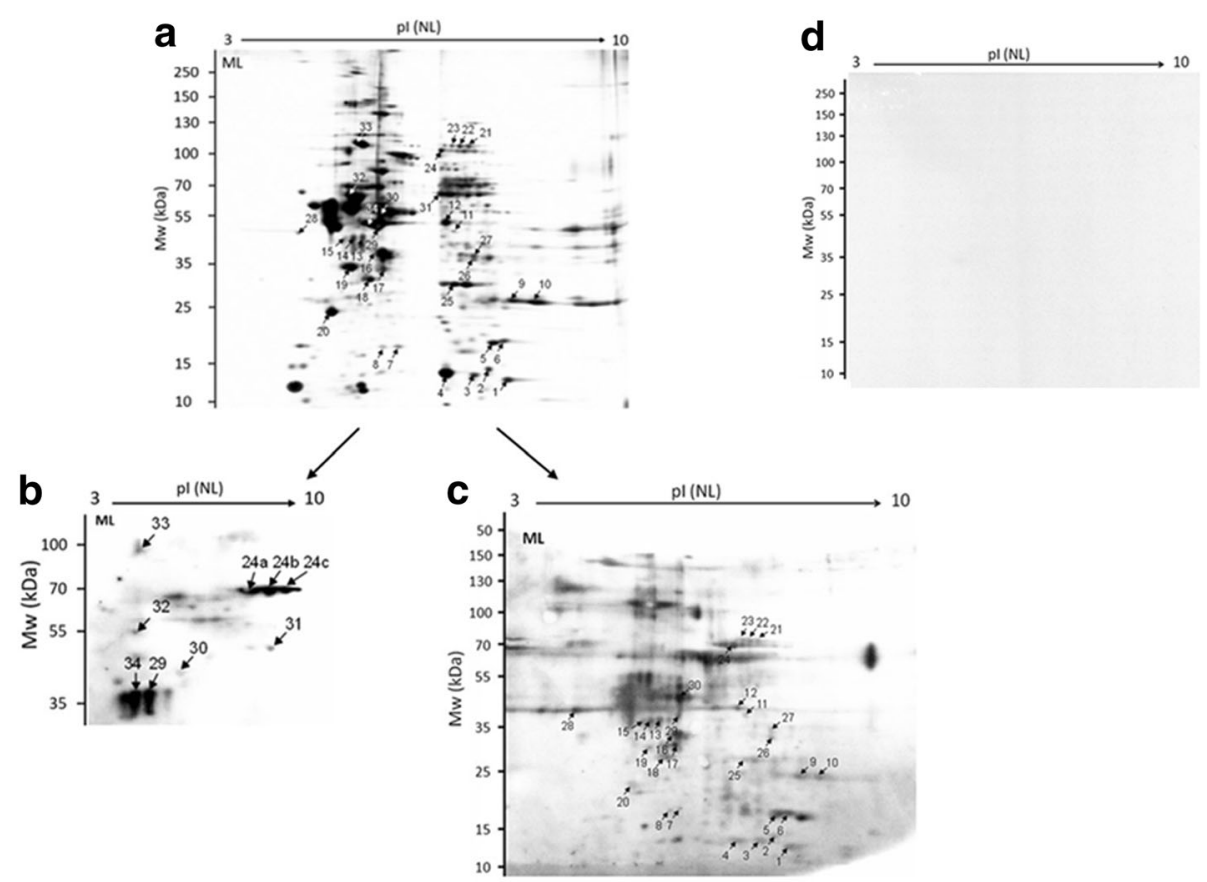

Fig. 2 An image of 2-DE separations and immunoblot analysis of somatic antigen extract of T. britovi muscle larvae (ML). a 2-DE gels were stained with a silver stain. 2D-immunoblot of ML proteins were probed with infected pig sera at $10 \mathrm{dpi}$ (b) and at $60 \mathrm{dpi}(\mathbf{c})$. d 2D- immunoblot of ML proteins probed with uninfected swine sera. Matched spots selected for subsequent LC-MS/MS analysis are marked

dpi, two spots - ML $60 \mathrm{dpi}$ ); tropomyosin (present in one spot - Ad $10 \mathrm{dpi}$, four spots - ML $60 \mathrm{dpi}$ ); and heat-shock $70 \mathrm{kDa}$ protein (present in four spots - Ad $10 \mathrm{dpi}$, one spot - ML $60 \mathrm{dpi}$ ) (Tables 1, 3, 4 and 7). The presence of these different isoforms could be attributed to differences in amino acid sequence, alternative splicing or post-translational modifications. The dominant proteins for both stages were identified as heat-shock protein $70 \mathrm{kDa}$, heat-shock protein beta-1, intermediate filament B and IFA-1 (Table 7).

\section{Gene ontology (GO) analysis}

The gene ontology (GO) database was used to identify the antigenic proteins of the Ad and ML stages according to their molecular function, cellular component and biological process.

For the T. britovi adult stage, the proteins were classified according to molecular function (39), cellular components (21) and biological process (21). Seven subcategories of molecular function were determined, the most abundant of which were binding (24) and catalytic activity (18); however, structural molecule activity (6), molecular function regulation (3), transporter activity (2), signal transducer (1) or peroxiredoxin activity (1) subcategories were also observed. Eight subcategories for cellular component were determined, the most numerous being the cell part subcategory (18); however, intracellular organelle part (7), macromolecular complex (7), organelle (6), membrane part (5), intermediate filament (4), membrane (3) or cell (1) subcategories were also observed to a lesser extent. Seven subcategories of biological process were determined. The most abundant were assigned to the cellular process (16) and the metabolic process (11) subcategories, while the remainder were assigned to biological regulation (5), localization (3), transport (2), response to oxidative stress (1), cell adhesion (1) or cellular component organization (1) (Fig. 3a-c). Based on the gene ontology analysis, the potentially antigenic proteins of $T$. britovi muscle larvae which reacted with both $10 \mathrm{dpi}$ and $60 \mathrm{dpi}$ pig sera, were categorized according to molecular function (35), cellular component (24) or biological process (18). Six subcategories for molecular function were determined. The most abundant were binding (20), and catalytic activity (20), whereas structural molecule activity (6), transmembrane transporter activity (3), molecular function regulation (2) or peroxiredoxin activity (1) were visibly less numerous. Eight cellular component subcategories were determined, with the most numerous subcategory being cell part (18), followed by intracellular organelle part (9), macromolecular complex (7), polymeric cytoskeletal fiber (6), membrane part (5), membrane (3), organelle (3) and cell (1). Four subcategories for biological process were determined. The cellular process (15) subcategory was the most numerous, followed by metabolic process (11), biological regulation (5) and localization (5) (Fig. 3a-c). 
Table 1 Results of LC-MS/MS analysis of Trichinella britovi adult worms (Ad) selected spots which reacted with pig sera collected at $10 \mathrm{dpi}$

\begin{tabular}{|c|c|c|c|c|c|c|c|c|}
\hline Spot & NCBlprot accession no. & $\mathrm{MS}^{\mathrm{a}}$ & $M \mathrm{P}^{\mathrm{b}}$ & Seq $^{c}$ & SC (\%) ${ }^{d}$ & emPAl ${ }^{e}$ & $\operatorname{Mr}(\mathrm{kDa}) / \mathrm{pl} \mathrm{f}^{f}$ & Description \\
\hline \multirow[t]{2}{*}{1} & KRZ04300.1 & 746 & 11 & 10 & 15 & 0.82 & $71.823 / 6.58$ & Transketolase, partial \\
\hline & KRY23714.1 & 363 & 5 & 5 & 8 & 0.33 & $75.949 / 8.54$ & $\begin{array}{l}\text { Succinate dehydrogenase (ubiquinone) } \\
\text { flavoprotein subunit, mitochondrial, partial }\end{array}$ \\
\hline 2 & KRY10810.1 & 817 & 13 & 11 & 16 & 1.08 & $70.999 / 6.60$ & Transketolase \\
\hline \multirow[t]{2}{*}{3} & KRY09282.1 & 1067 & 18 & 17 & 25 & 1.86 & $73.168 / 6.07$ & Intermediate filament protein ifa-1 \\
\hline & KRY23083.1 & 1015 & 16 & 16 & 22 & 1.19 & $76.326 / 6.17$ & Stress-70 protein, mitochondrial, partial \\
\hline 4 & KRY23083.1 & 405 & 6 & 6 & 10 & 0.32 & $76.326 / 6.17$ & Stress-70 protein, mitochondrial, partial \\
\hline \multirow[t]{2}{*}{5} & KRY23083.1 & 247 & 3 & 3 & 5 & 0.18 & $76.326 / 6.17$ & Stress-70 protein, mitochondrial, partial \\
\hline & KRZ06996.1 & 99 & 2 & 2 & 2 & 0.12 & $74.844 / 5.78$ & Intermediate filament protein ifa-1, partial \\
\hline \multirow[t]{4}{*}{6} & KRY11608.1 & 1889 & 36 & 26 & 40 & 4.74 & $75.526 / 6.24$ & Intermediate filament protein B \\
\hline & KRY09282.1 & 1883 & 31 & 27 & 38 & 4.10 & $73.168 / 6.07$ & Intermediate filament protein ifa-1 \\
\hline & KRY16427.1 & 1772 & 33 & 22 & 22 & 1.78 & $108.386 / 6.14$ & Heat-shock cognate $71 \mathrm{kDa}$ protein, partial \\
\hline & CAA73574.1 & 1612 & 30 & 21 & 31 & 3.15 & $71.860 / 5.77$ & Heat-shock protein 70 \\
\hline \multirow[t]{4}{*}{7} & KRY58599.1 & 1946 & 38 & 26 & 23 & 1.54 & $131.529 / 6.88$ & Heat-shock cognate $71 \mathrm{kDa}$ protein, partial \\
\hline & KRY11608.1 & 1933 & 37 & 23 & 38 & 5.03 & $75.526 / 6.24$ & Intermediate filament protein B \\
\hline & CAA73574.1 & 1773 & 32 & 25 & 36 & 3.87 & $71.860 / 5.77$ & Heat-shock protein 70 \\
\hline & KRY09282.1 & 1503 & 25 & 21 & 29 & 2.95 & $73.168 / 6.07$ & Intermediate filament protein ifa-1 \\
\hline \multirow[t]{3}{*}{8} & CAA73574.1 & 1633 & 35 & 22 & 33 & 3.42 & $71.860 / 5.77$ & Heat-shock protein 70 \\
\hline & KRY11608.1 & 1094 & 18 & 17 & 25 & 1.62 & $75.526 / 6.24$ & Intermediate filament protein B \\
\hline & KRZ06996.1 & 906 & 13 & 12 & 17 & 0.98 & $74.844 / 5.78$ & Intermediate filament protein ifa-1, partial \\
\hline \multirow[t]{2}{*}{9} & KRY21440.1 & 646 & 12 & 9 & 16 & 0.97 & $62.134 / 5.04$ & Calreticulin \\
\hline & KRY19442.1 & 329 & 5 & 5 & 15 & 0.81 & $35.572 / 9.61$ & Y-box factor -like protein \\
\hline \multirow[t]{2}{*}{10} & KRY21426.1 & 507 & 8 & 7 & 27 & 1.80 & $29.821 / 4.64$ & Myosin light chain kinase, smooth muscle \\
\hline & AET09716.1 & 215 & 3 & 3 & 15 & 0.78 & $22.620 / 4.54$ & Tropomyosin, partial \\
\hline 11 & KRZ13803.1 & 412 & 6 & 5 & 17 & 1.07 & $35.565 / 8.61$ & $\begin{array}{l}32 \mathrm{kDa} \text { beta-galactoside-binding lectin } \\
\text { lec-3 (Galectin) }\end{array}$ \\
\hline 12 & KRY20423.1 & 465 & 8 & 6 & 21 & 1.48 & $33.995 / 7.69$ & $\begin{array}{l}32 \mathrm{kDa} \text { beta-galactoside-binding } \\
\text { lectin (Galectin) }\end{array}$ \\
\hline 13 & KRX13351.1 & 62 & 1 & 1 & 4 & 0.15 & $29.477 / 8.21$ & RNA-binding protein rnp-1 \\
\hline 14 & KRX46812.1 & 497 & 7 & 6 & 32 & 2.26 & $22.941 / 7.07$ & Peroxiredoxin-2, partial \\
\hline \multirow[t]{2}{*}{15} & KRZ77496.1 & 378 & 6 & 4 & 3 & 0.08 & $23.7876 / 6.48$ & Dedicator of cytokinesis protein 1 \\
\hline & KRY20040.1 & 140 & 3 & 2 & 10 & 0.97 & $18.977 / 6.97$ & Heat-shock protein beta-1 \\
\hline \multirow[t]{2}{*}{16} & KRY20040.1 & 445 & 12 & 6 & 34 & 3.69 & $18.977 / 6.97$ & Heat-shock protein beta-1 \\
\hline & KRX20324.1 & 323 & 6 & 4 & 28 & 1.33 & 19.886/8.12 & OV-16 antigen, partial \\
\hline \multirow[t]{2}{*}{17} & KRY20040.1 & 405 & 11 & 5 & 30 & 3.01 & $18.977 / 6.97$ & Heat-shock protein beta-1 \\
\hline & KRX20324.1 & 369 & 6 & 4 & 28 & 1.43 & $19.886 / 8.12$ & OV-16 antigen, partial \\
\hline \multirow[t]{2}{*}{18} & KRX47621.1 & 701 & 19 & 9 & 53 & 7.94 & $18.951 / 6.97$ & Heat-shock protein beta-1 \\
\hline & KRX19442.1 & 106 & 2 & 2 & 10 & 0.57 & $18.490 / 8.74$ & Transcription factor BTF3 -like protein 4 \\
\hline \multirow[t]{4}{*}{19} & KRX16844.1 & 358 & 11 & 6 & 30 & 2.86 & $18.894 / 6.32$ & Alpha-crystallin B chain \\
\hline & KRY20040.1 & 297 & 6 & 4 & 26 & 2.06 & $18.977 / 6.97$ & Heat-shock protein beta-1 \\
\hline & KRZ07637.1 & 278 & 3 & 3 & 14 & 0.75 & $23.026 / 6.12$ & Stromal cell-derived factor 2 \\
\hline & KRZ08373.1 & 75 & 2 & 2 & 9 & 0.47 & $22.324 / 7.68$ & Peroxiredoxin-2 \\
\hline \multirow[t]{2}{*}{20} & KRX18074.1 & 398 & 8 & 6 & 9 & 0.74 & $54.209 / 4.92$ & $\begin{array}{l}\text { BAG family molecular chaperone } \\
\text { regulator 2, partial }\end{array}$ \\
\hline & KRZ17076.1 & 165 & 3 & 2 & 10 & 0.75 & $22.920 / 5.45$ & Rho GDP-dissociation inhibitor 1 \\
\hline
\end{tabular}


Table 1 Results of LC-MS/MS analysis of Trichinella britovi adult worms (Ad) selected spots which reacted with pig sera collected at $10 \mathrm{dpi}$ (Continued)

\begin{tabular}{|c|c|c|c|c|c|c|c|c|}
\hline Spot & NCBlprot accession no. & $M^{a}$ & $M P^{b}$ & $\mathrm{Seq}^{\mathrm{C}}$ & SC $(\%)^{d}$ & emPAl $^{e}$ & $\mathrm{Mr}(\mathrm{kDa}) / \mathrm{pl}{ }^{f}$ & Description \\
\hline 21 & Unidentified & - & - & - & - & - & - & - \\
\hline \multirow[t]{5}{*}{22} & KRY31449.1 & 1224 & 26 & 15 & 20 & 1.11 & $91.608 / 5.31$ & $\begin{array}{l}\text { Transitional endoplasmic reticulum ATPase - } \\
\text { like protein } 2\end{array}$ \\
\hline & KRZ08767.1 & 1011 & 13 & 13 & 7 & 0.27 & $234.755 / 5.91$ & Myosin-4, partial \\
\hline & KRZ03705.1 & 287 & 3 & 3 & 4 & 0.13 & $101.672 / 5.38$ & Paramyosin \\
\hline & KRY00202.1 & 206 & 4 & 3 & 5 & 0.20 & $92.727 / 5.26$ & Heat-shock 70 kDa protein 4L \\
\hline & KRY14731.1 & 172 & 3 & 3 & 3 & 0.10 & $131.892 / 6.63$ & CAP-Gly domain-containing linker protein 1 \\
\hline \multirow[t]{3}{*}{23} & KRY18882.1 & 994 & 15 & 12 & 14 & 0.79 & 108.605/5.51 & LIM domain and actin-binding protein 1 \\
\hline & KRZ08767.1 & 345 & 6 & 6 & 3 & 0.12 & $234.755 / 5.91$ & Myosin-4, partial \\
\hline & KRZ13693.1 & 302 & 5 & 5 & 4 & 0.20 & $125.148 / 6.31$ & Integrin alpha pat-2 \\
\hline 24 & KRZ06959.1 & 252 & 3 & 3 & 11 & 0.61 & $28.479 / 7.74$ & Triosephosphate isomerase, partial \\
\hline 25 & KRZ12367.1 & 299 & 4 & 4 & 24 & 1.19 & $24.385 / 7.01$ & GTP-binding nuclear protein Ran \\
\hline \multirow[t]{3}{*}{26} & KRX15368.1 & 656 & 14 & 10 & 33 & 3.52 & $34.025 / 6.29$ & 32 kDa beta-galactoside-binding lectin, partial \\
\hline & KRY59871.1 & 115 & 2 & 2 & 12 & 0.32 & $30.478 / 9.08$ & Serine/arginine-rich splicing factor 1, partial \\
\hline & KRX23478.1 & 101 & 2 & 2 & 4 & 0.27 & $35.530 / 6.82$ & Protein MEMO1, partial \\
\hline \multirow[t]{3}{*}{27} & KRX41818.1 & 376 & 5 & 5 & 21 & 1.13 & $29.431 / 5.58$ & Putative phosphomannomutase \\
\hline & KRY00151.1 & 137 & 3 & 2 & 4 & 0.25 & $59.844 / 5.54$ & ATP synthase subunit beta, mitochondrial \\
\hline & KRY00848.1 & 114 & 2 & 2 & 2 & 0.09 & 108.425/6.27 & Heat-shock 70 kDa protein, partial \\
\hline \multirow[t]{3}{*}{28} & KRX20997.1 & 368 & 6 & 6 & 8 & 0.40 & $76.565 / 8.34$ & $\begin{array}{l}\text { Guanine nucleotide-binding } \\
\text { proteinalpha-12 subunit, partial }\end{array}$ \\
\hline & KRX16428.1 & 294 & 6 & 5 & 23 & 1.65 & $26.141 / 5.80$ & V-type proton ATPase subunit E \\
\hline & KRZ10894.1 & 177 & 3 & 3 & 9 & 0.58 & $27.709 / 7.55$ & GrpE -like protein 1, mitochondrial \\
\hline 29 & KRY01036.1 & 394 & 8 & 5 & 27 & 2.16 & $22.274 / 6.88$ & Actin-depolymerizing factor 1 , isoforms a/b, partial \\
\hline \multirow[t]{3}{*}{30} & KRY01036.1 & 440 & 8 & 5 & 27 & 2.12 & $22.274 / 6.88$ & Actin-depolymerizing factor 1 , isoforms a/b, partial \\
\hline & KRY17912.1 & 295 & 4 & 4 & 18 & 1.63 & $17.440 / 6.18$ & Uncharacterized protein T12_13420 \\
\hline & KRY00151.1 & 143 & 4 & 2 & 4 & 0.33 & $59.844 / 5.54$ & ATP synthase subunit beta, mitochondrial \\
\hline \multirow[t]{3}{*}{31} & KRY01216.1 & 278 & 5 & 5 & 21 & 1.85 & $19885 / 5.43$ & Ubiquitin-conjugating enzyme E2 G1, partial \\
\hline & KRY21297.1 & 199 & 4 & 3 & 14 & 1.15 & $21.790 / 8.89$ & Peptide methionine sulfoxide reductase MsrB \\
\hline & KRY15966.1 & 185 & 4 & 3 & 10 & 0.44 & $34.259 / 6.31$ & Hypothetical protein T12_8663 \\
\hline
\end{tabular}

\footnotetext{
${ }^{\mathrm{a}}$ Mascot score

${ }^{b}$ Matched peptide

'Sequence

${ }^{\mathrm{d}}$ Sequence coverage (\%)

${ }^{\mathrm{e}}$ Exponentially modified protein abundance index

Experimental nominal mass $(\mathrm{kDa})$ and isoelectric point
}

\section{Discussion}

Recent reports indicate most cases of Trichinella britovi infection occur amongst patients unaware of eating improperly cooked meat products [32-34, 38]. Early diagnosis of trichinellosis is crucial, as anthelmintic drug treatment is much more effective if administered during the initial phases before muscle larvae become encapsulated [39].

In trichinellosis, the interaction between the parasite and the host is influenced by the Trichinella life-cycle, which includes a range of stage-specific antigens, immune evasion strategies and modulatory effects on host responses. The combination of immunoblot analysis and proteomic techniques, such as the two-dimensional gel electrophoresis and mass spectrometry used in the present study, is a comprehensive approach to identifying Trichinella proteins [40]. Although most proteomic studies have focused on the identification of proteins characteristic of $T$. spiralis life-cycle stages, same of them were dedicated to other Trichinella species/genotypes including T. pseudospiralis, T. nativa, T. papuae and T8 [18, 19, 21, 26, 41].

However, further effort is still needed to identify the T. britovi proteins that may play an important role in 
Table 2 Alphabetical list of stage-specific antigenic proteins of adult worms of T. britovi, which reacted with pig sera collected at $10 \mathrm{dpi}$, together with spot number information. Identification by LC-MS/MS

\begin{tabular}{|c|c|}
\hline Protein name & Spot number \\
\hline Actin-depolymerizing factor 1 , isoforms a/b, partial & 29,30 \\
\hline BAG family molecular chaperone regulator 2 , partial & 20 \\
\hline Calreticulin & 9 \\
\hline CAP-Gly domain-containing linker protein 1 & 22 \\
\hline GrpE-like protein 1, mitochondrial & 28 \\
\hline $\begin{array}{l}\text { Guanine nucleotide-binding protein alpha-12 } \\
\text { subunit, partial }\end{array}$ & 28 \\
\hline Heat-shock $70 \mathrm{kDa}$ protein 4L & 22 \\
\hline Heat-shock cognate 71 kDa protein, partial & 6,7 \\
\hline Hypothetical protein T12_8663 & 31 \\
\hline Integrin alpha pat-2 & 23 \\
\hline LIM domain and actin-binding protein 1 & 23 \\
\hline Myosin-4, partial & 22,23 \\
\hline Myosin light chain kinase, smooth muscle & 10 \\
\hline Paramyosin & 22 \\
\hline Peptide methionine sulfoxide reductase MsrB & 31 \\
\hline Putative phosphomannomutase & 27 \\
\hline Rho GDP-dissociation inhibitor 1 & 20 \\
\hline RNA-binding protein rnp-1 & 13 \\
\hline Serine/arginine-rich splicing factor 1, partial & 26 \\
\hline Stress-70 protein, mitochondrial & $3,4,5$ \\
\hline Stromal cell-derived factor 2 & 19 \\
\hline $\begin{array}{l}\text { Succinate dehydrogenase (ubiquinone) } \\
\text { flavoprotein subunit, mitochondrial, partial }\end{array}$ & 1 \\
\hline $\begin{array}{l}\text { Transitional endoplasmic reticulum ATPase } \\
\text {-like protein } 2\end{array}$ & 22 \\
\hline Transketolase /partial & 1,2 \\
\hline Triosephosphate isomerase, partial & 24 \\
\hline Ubiquitin-conjugating enzyme E2 G1, partial & 31 \\
\hline Uncharacterized protein T12_13420 & 30 \\
\hline Y-box factor -like protein & 9 \\
\hline V-type proton ATPase subunit E & 28 \\
\hline
\end{tabular}

understanding host-parasite interactions, and to develop immunological diagnostic methods. Only two papers have addressed the identification of antigenic proteins from $T$. britovi, the second-most common species of Trichinella that may affect human health $[9$, 30]. Dea-Ayuela \& Bolaz-Fernandez [30], using 2-DE immunoblot, identified the T. britovi proteins that likely belong to the Trichinella TSL-1 group of antigens: enolase; P49 antigen; and actins. These proteins play a part in parasite invasion and migration through the host cells. Other studies based on the immunoproteomics of the excretory-secretory systems of $T$. britovi muscle larvae identified a range of proteins, including various glycoproteins (gp43, p49), serine-protease and 5'-nucleotidase [9], that play a role in the development and migration of NBL in host tissue and in the regulation of the immune response by modulating nucleotide levels during infection [42].

The purpose of the present study, therefore, was to identify the $T$. britovi-specific immunodominant proteins present in adult worms and muscle larvae. The crude protein extracts of both stages were separated by 2-DE, subjected to immunoblot analysis with sera from animals infected with T. britovi (at $10 \mathrm{dpi}$ and $60 \mathrm{dpi}$ ), and identified by LC-MS/MS. A previous immunoproteomic study performed on T. spiralis antigens showed that 64 proteins from adult worm crude extract were recognized by sera from pigs and mice infected with $T$. spiralis at $7 \mathrm{dpi}$, but only seven proteins in muscle larvae crude extract were detected using sera from $T$. spiralis-infected mice and pigs at $5 \mathrm{dpi}$ and $45 \mathrm{dpi}$, respectively $[11,15,27]$.

In the present study, the immunogenic spots recognized by the various pig $T$. britovi-infected sera were divided into three groups according to immunoblotting pattern and LC-MS/MS results: adult (Ad) stage-specific proteins; muscle larvae (ML) stage-specific proteins; and proteins common to both developmental stages. Forty-five proteins in the Ad samples (29 stage-specific for Ad and 16 common) and 13 proteins in the ML samples (9 stage-specific for ML and 4 common) cross-reacted with sera at 10 dpi, while 39 proteins in the ML samples (25 stage-specific for ML and 14 common) reacted with the sera taken at $60 \mathrm{dpi}$.

Additionally, to further understand the functions of the $T$. britovi proteins, these proteins were categorized according to the GO into biological processes, molecular function and cellular components. The results reveal the presence of a range of proteins known to be antigens involved in the mechanisms of invasion of host tissue and cells, larval migration or molting, immune modulation, metabolic processes in other helminths: actin; heat-shock proteins; paramyosin; 14-3-3-protein; myosin; serine protease; enolase; poly-cysteine and histidine-tailed protein; and deoxyribonuclease-2-alpha [21, 26, 27, 43-45]. Of these proteins, the following were common for both tested T. britovi stages: $32 \mathrm{kDa}$ beta galactoside-binding lectin lec-3 (Galectin); heat-shock $70 \mathrm{kDa}$ protein; heat-shock protein beta-1; intermediate filament protein IFA-1; intermediate filament protein B; GTP-binding nuclear protein Ran; OV-16 antigen; protein MEMO1; transcription factor BTF3-like protein 4; tropomyosin; and peroxiredoxin-2. These have previously been found to be present and active throughout the parasite development process; however, they were present in varying amounts, as indicated by the observed dissimilarities in spot intensities. 
Table 3 Results of LC-MS/MS analysis of Trichinella britovi muscle larvae (ML) selected spots which reacted with pig sera collected at $10 \mathrm{dpi}$

\begin{tabular}{|c|c|c|c|c|c|c|c|c|c|}
\hline Spot & & NCBlprot accession No. & $\mathrm{MS}^{\mathrm{a}}$ & $M P^{b}$ & $\mathrm{Seq}^{\mathrm{c}}$ & SC (\%) $)^{d}$ & emPAl ${ }^{\mathrm{e}}$ & $\operatorname{Mr}(\mathrm{kDa}) / \mathrm{pl}^{f}$ & Description \\
\hline \multirow[t]{6}{*}{24} & a & KRY11608.1 & 1765 & 36 & 26 & 36 & 4.01 & $75.526 / 6.24$ & Intermediate filament protein B \\
\hline & & KRY09282.1 & 1457 & 30 & 22 & 30 & 2.92 & $73.168 / 6.07$ & Intermediate filament protein ifa-1 \\
\hline & $b$ & KRY11608.1 & 1903 & 40 & 29 & 39 & 5.11 & $75.526 / 6.24$ & Intermediate filament protein B \\
\hline & & KRY09282.1 & 1541 & 33 & 23 & 33 & 3.30 & $73.168 / 6.07$ & Intermediate filament protein ifa-1 \\
\hline & c & KRY11608.1 & 930 & 14 & 13 & 19 & 1.24 & $75.526 / 6.24$ & Intermediate filament protein B \\
\hline & & KRY09282.1 & 2328 & 66 & 34 & 47 & 7.99 & $73.168 / 6.07$ & Intermediate filament protein ifa-1 \\
\hline 29 & & XP_003373575.1 & 1206 & 52 & 15 & 41 & 4.74 & $42.210 / 5.30$ & Actin-5C \\
\hline \multirow[t]{5}{*}{30} & & XP_003373575.1 & 527 & 9 & 8 & 25 & 1.47 & $42.210 / 5.30$ & Actin-5C \\
\hline & & KRY50178.1 & 415 & 8 & 6 & 15 & 0.89 & $46.783 / 5.44$ & Hypothetical protein T03_17187 \\
\hline & & KRZ06996.1 & 160 & 3 & 3 & 4 & 0.12 & $74.844 / 5.78$ & $\begin{array}{l}\text { Intermediate filament protein ifa- } 1 \text {, } \\
\text { partial }\end{array}$ \\
\hline & & KRZ09733.1 & 323 & 5 & 5 & 5 & 0.28 & $96.031 / 6.00$ & $\begin{array}{l}\text { Mitochondrial-processing peptidase } \\
\text { subunit beta, partial }\end{array}$ \\
\hline & & KRX47705.1 & 293 & 4 & 4 & 3 & 0.14 & $150.442 / 6.28$ & Serine protease 30 \\
\hline \multirow{2}{*}{\multicolumn{2}{|c|}{31}} & KRZ02603.1 & 1083 & 28 & 14 & 34 & 2.98 & $50.922 / 6.01$ & Enolase, partial \\
\hline & & KRY13126.1 & 544 & 10 & 9 & 20 & 1.47 & $48.623 / 5.41$ & 265 protease regulatory subunit 7 \\
\hline \multirow[t]{3}{*}{32} & & KRY18793.1 & 883 & 19 & 14 & 30 & 3.45 & $54.997 / 5.00$ & Protein disulfide-isomerase 2 \\
\hline & & OUC40875.1 & 749 & 17 & 10 & 26 & 2.73 & $48.387 / 4.87$ & $\begin{array}{l}\text { Putative Tubulin/FtsZ family, GTPase } \\
\text { domain protein }\end{array}$ \\
\hline & & KRY00151.1 & 655 & 14 & 8 & 17 & 1.31 & $59.844 / 5.54$ & ATP synthase subunit beta, mitochondrial \\
\hline \multirow{2}{*}{\multicolumn{2}{|c|}{33}} & KRX41020.1 & 1127 & 27 & 16 & 27 & 1.92 & $72.856 / 5.09$ & Heat-shock 70 kDa protein C, partial \\
\hline & & KRY00702.1 & 364 & 6 & 5 & 9 & 0.46 & $68.894 / 5.08$ & V-type proton ATPase catalytic subunit A \\
\hline 34 & & Unidentified & - & - & - & - & - & - & - \\
\hline
\end{tabular}

${ }^{\mathrm{a}}$ Mascot score

${ }^{\mathrm{b}}$ Matched peptide

'Sequence

${ }^{\mathrm{d}}$ Sequence coverage (\%)

exponentially modified protein abundance index

${ }^{\mathrm{f}}$ Experimental nominal mass $(\mathrm{kDa})$ and isoelectric point

Adult T. britovi are frequently found to contain proteins involved in structural and motor activity, such as myosin-4, myosin light chain kinase, paramyosin, intermediate filament protein $\mathrm{B}$, actin-depolymerizing factor 1 and calreticulin. These cytoskeleton proteins with an actin binding function, are responsible for cellular component organization and actin filament depolymerization, thus facilitating the parasite growth and development processes. Some of them, including actin-depolymerizing factor 1 and paramyosin, were identified in the ML stage but not the early stage of Trichinella development $[11,46]$. One of these, carleticulin, belongs to the carleticulin family of proteins, which are involved in the protein folding process, and were recently reported to facilitate $T$. spiralis immune evasion by interacting with the first component of the human classical complement pathway, C1q [47]. In addition to its role in muscle length and stability determination, paramyosin also possess immunomodulatory functions. The surface-exposed paramyosin is thought to act as a protective agent during the host inflammatory processes by inhibiting the complement activation cascade and membrane attack complex (MAC) formation [48]. However, V-type proton ATPase subunit E, a member of the ATPase protein family, is activated at a wide $\mathrm{pH}$ range and possesses interesting properties under certain biochemical conditions. ATPases are involved in metabolite movements, purging of toxins and energy generation for metabolic processes; they also take part in the environmental response $[49,50]$ and hence are thought to be involved in the nematode immune response course. Most of the analyzed T. britovi antigens are derived from the muscle stage of the larvae. GO analysis of the obtained results showed that some of the proteins participate in various cellular and metabolic processes mostly associated with the synthesis and degradation of macromolecules (nucleotides, proteins) which play an important role in the invasion 
Table 4 Results of LC-MS/MS analysis of Trichinella britovi muscle larvae (ML) selected spots which reacted with pig sera collected at $60 \mathrm{dpi}$

\begin{tabular}{|c|c|c|c|c|c|c|c|c|}
\hline Spot & NCBlprot accession No. & $\mathrm{MS}^{\mathrm{a}}$ & $M P^{b}$ & Seq $^{c}$ & SC $(\%)^{d}$ & emPAl $^{\mathrm{e}}$ & $\operatorname{Mr}(\mathrm{kDa}) / \mathrm{pl} \mathrm{f}^{\mathrm{f}}$ & Description \\
\hline \multirow[t]{2}{*}{1} & KRX47621.1 & 732 & 22 & 10 & 53 & 13.42 & $18.951 / 6.97$ & Heat-shock protein beta-1 \\
\hline & KRX19442.1 & 133 & 2 & 2 & 10 & 0.64 & $18.490 / 8.74$ & Transcription factor BTF3 -like protein 4 \\
\hline \multirow[t]{2}{*}{2} & KRX14469.1 & 241 & 3 & 3 & 2 & 0.06 & $247.333 / 6.85$ & Dedicator of cytokinesis protein 1 \\
\hline & KRZ13097.1 & 165 & 5 & 3 & 13 & 1.75 & $19.090 / 5.43$ & Heat-shock protein beta-1, partial \\
\hline \multirow[t]{2}{*}{3} & KRY20040.1 & 376 & 8 & 6 & 34 & 4.92 & $18.977 / 6.97$ & Heat-shock protein beta-1 \\
\hline & KRX20324.1 & 310 & 5 & 4 & 28 & 1.64 & $19.886 / 8.12$ & OV-16 antigen, partial \\
\hline \multirow[t]{3}{*}{4} & KRX16844.1 & 662 & 60 & 10 & 66 & 10.33 & $18.894 / 6.32$ & Alpha-crystallin B chain \\
\hline & KRY20040.1 & 396 & 8 & 7 & 35 & 4.78 & $18.977 / 6.97$ & Heat-shock protein beta-1 \\
\hline & KRY18783.1 & 109 & 2 & 2 & 9 & 0.18 & $25.119 / 6.44$ & Stromal cell-derived factor 2 \\
\hline 5 & KRX46812.1 & 546 & 11 & 8 & 41 & 4.02 & $22.941 / 7.07$ & Peroxiredoxin-2, partial \\
\hline \multirow[t]{3}{*}{6} & KRX46812.1 & 409 & 8 & 6 & 28 & 2.07 & $22.941 / 7.07$ & Peroxiredoxin-2, partial \\
\hline & KRZ12367.1 & 292 & 4 & 4 & 19 & 1.02 & $24.385 / 7.01$ & GTP-binding nuclear protein Ran \\
\hline & KRX18658.1 & 226 & 3 & 3 & 15 & 0.73 & $23.516 / 6.92$ & ATP synthase subunit $d$, mitochondrial \\
\hline 7 & Unidentified & - & - & - & - & - & - & - \\
\hline 8 & Unidentified & - & - & - & - & - & - & - \\
\hline 9 & KRZ13803.1 & 406 & 7 & 5 & 17 & 1.11 & $35.565 / 8.61$ & $\begin{array}{l}32 \mathrm{kDa} \text { beta-galactoside-binding lectin } \\
\text { lec-3 (Galectin) }\end{array}$ \\
\hline \multirow[t]{2}{*}{10} & KRZ13803.1 & 584 & 9 & 7 & 24 & 1.58 & $35.565 / 8.61$ & $\begin{array}{l}32 \text { kDa beta-galactoside-binding lectin } \\
\text { lec-3 (Galectin) }\end{array}$ \\
\hline & KRY30017.1 & 304 & 6 & 5 & 17 & 0.82 & $34.995 / 8.74$ & Putative 3-hydroxyacyl-CoA dehydrogenase \\
\hline 11 & KRZ13161.1 & 105 & 2 & 2 & 6 & 0.23 & $42.112 / 7.12$ & Glutamine synthetase \\
\hline \multirow[t]{3}{*}{12} & KRY11984.1 & 432 & 7 & 7 & 15 & 0.90 & $49.560 / 6.59$ & Poly-cysteine and histidine-tailed protein \\
\hline & KRX28313.1 & 364 & 7 & 6 & 14 & 1.01 & $45.667 / 6.09$ & Calponin -like protein OV9M, partial \\
\hline & KRX47308.1 & 240 & 3 & 3 & 3 & 0.14 & $107.151 / 6.52$ & Deoxyribonuclease-2-alpha \\
\hline 13 & KRY01407.1 & 324 & 4 & 4 & 10 & 0.46 & $51.099 / 5.91$ & Cuticlin-1, partial \\
\hline \multirow[t]{2}{*}{14} & KRY01407.1 & 319 & 4 & 4 & 10 & 0.48 & $51.099 / 5.91$ & Cuticlin-1, partial \\
\hline & KRY00848.1 & 166 & 3 & 3 & 2 & 0.15 & $108.425 / 6.27$ & Heat-shock 70 kDa protein, partial \\
\hline 15 & CBX25713.1 & 322 & 5 & 5 & 14 & 1.14 & $32.896 / 4.65$ & Tropomyosin, partial \\
\hline \multirow[t]{2}{*}{16} & KRY09099.1 & 476 & 8 & 8 & 22 & 1.47 & $38.218 / 5.20$ & Hypothetical protein T12_13379, partial \\
\hline & KRX15676.1 & 174 & 3 & 3 & 7 & 0.43 & $35.904 / 5.46$ & $40 \mathrm{~S}$ ribosomal protein SA, partial \\
\hline \multirow[t]{4}{*}{17} & KRY09099.1 & 381 & 6 & 6 & 16 & 1.20 & $38.218 / 5.20$ & Hypothetical protein T12_13379, partial \\
\hline & KRZ15717.1 & 217 & 4 & 3 & 9 & 0.46 & $39.852 / 5.63$ & $\begin{array}{l}\text { Guanine nucleotide-binding protein } \\
\text { subunit beta-1, partial }\end{array}$ \\
\hline & KRY18502.1 & 203 & 4 & 3 & 3 & 0.26 & $65.700 / 4.95$ & $\begin{array}{l}\text { Microtubule-associated protein RP/EB } \\
\text { family member 3, partial }\end{array}$ \\
\hline & KRX15059.1 & 126 & 3 & 2 & 5 & 0.52 & $36.189 / 5.00$ & Disorganized muscle protein 1 \\
\hline 18 & KRX21567.1 & 504 & 11 & 6 & 21 & 1.66 & $40.427 / 5.49$ & $\begin{array}{l}\text { Pyruvate dehydrogenase E1 component } \\
\text { subunit beta, mitochondrial }\end{array}$ \\
\hline \multirow[t]{2}{*}{19} & KRX15059.1 & 667 & 23 & 9 & 28 & 2.96 & $36.189 / 5.00$ & Disorganized muscle protein 1 \\
\hline & KRZ03570.1 & 403 & 6 & 6 & 18 & 1.20 & $34.457 / 4.75$ & Tropomyosin \\
\hline \multirow[t]{3}{*}{20} & XP_003378934.1 & 1001 & 20 & 12 & 46 & 6.93 & $28.294 / 4.83$ & 14-3-3 protein zeta \\
\hline & AET09716.1 & 248 & 4 & 4 & 19 & 1.09 & $22.620 / 4.54$ & Tropomyosin, partial \\
\hline & KRX19348.1 & 159 & 3 & 3 & 13 & 0.56 & $28.034 / 4.82$ & Toll-interacting protein \\
\hline 21 & KRZ50222.1 & 917 & 16 & 14 & 3 & 0.17 & $449.723 / 6.87$ & $\begin{array}{l}\text { Propionyl-CoA carboxylase alpha } \\
\text { chain, mitochondrial }\end{array}$ \\
\hline
\end{tabular}


Table 4 Results of LC-MS/MS analysis of Trichinella britovi muscle larvae (ML) selected spots which reacted with pig sera collected at $60 \mathrm{dpi}$ (Continued)

\begin{tabular}{|c|c|c|c|c|c|c|c|c|}
\hline Spot & NCBlprot accession No. & $\mathrm{MS}^{\mathrm{a}}$ & $M P^{b}$ & $\mathrm{Seq}^{\mathrm{c}}$ & SC (\%) ${ }^{d}$ & emPAl $^{e}$ & $\operatorname{Mr}(\mathrm{kDa}) / \mathrm{pl}{ }^{f}$ & Description \\
\hline 22 & KRZ50222.1 & 1081 & 18 & 17 & 4 & 0.19 & $449.723 / 6.87$ & $\begin{array}{l}\text { Propionyl-CoA carboxylase alpha } \\
\text { chain, mitochondrial }\end{array}$ \\
\hline 23 & KRY09873.1 & 557 & 9 & 9 & 2 & 0.09 & $441.173 / 6.76$ & $\begin{array}{l}\text { Propionyl-CoA carboxylase alpha } \\
\text { chain, mitochondrial }\end{array}$ \\
\hline \multirow[t]{2}{*}{24} & KRY45949.1 & 1999 & 45 & 29 & 42 & 6.80 & $73.429 / 6.07$ & Intermediate filament protein ifa-1 \\
\hline & KRY09282.1 & 1720 & 36 & 26 & 36 & 4.01 & $75.526 / 6524$ & Intermediate filament protein B \\
\hline \multirow[t]{3}{*}{25} & KRX15368.1 & 437 & 7 & 7 & 20 & 1.80 & $34.025 / 6.29$ & $\begin{array}{l}32 \mathrm{kDa} \text { beta-galactoside-binding } \\
\text { lectin, partial }\end{array}$ \\
\hline & KRZ10402.1 & 91 & 2 & 2 & 4 & 0.33 & $35.568 / 6.67$ & Protein MEMO1, partial \\
\hline & KRZ78587.1 & 42 & 3 & 1 & 2 & 0.11 & $48.445 / 5.59$ & Secernin-3 \\
\hline 26 & KRY07641.1 & 341 & 6 & 5 & 18 & 1.14 & $38.033 / 6.38$ & 1,5-anhydro-D-fructose reductase \\
\hline 27 & KRY07641.1 & 239 & 4 & 4 & 12 & 0.63 & $38.033 / 6.38$ & 1,5-anhydro-D-fructose reductase \\
\hline 28 & Unidentified & - & - & - & - & - & - & - \\
\hline \multirow[t]{4}{*}{29} & XP_003373575.1 & 1255 & 39 & 15 & 41 & 4.48 & $42.210 / 5.30$ & Actin-5C \\
\hline & AET09716.1 & 168 & 2 & 2 & 11 & 0.45 & $22.620 / 4.54$ & Tropomyosin, partial \\
\hline & KRY38295.1 & 160 & 3 & 3 & 6 & 0.26 & $54.444 / 6.39$ & Secernin-3 \\
\hline & KRZ06996.1 & 232 & 3 & 3 & 4 & 0.19 & $74.844 / 5.78$ & $\begin{array}{l}\text { Intermediate filament protein ifa-1, } \\
\text { partial }\end{array}$ \\
\hline \multirow[t]{7}{*}{30} & KRY50178.1 & 993 & 18 & 15 & 40 & 4.11 & $46.783 / 5.44$ & Hypothetical protein T03_17187 \\
\hline & XP_003373575.1 & 527 & 9 & 8 & 25 & 1.47 & $42.210 / 5.30$ & Actin-5C \\
\hline & KRZ06996.1 & 363 & 6 & 6 & 9 & 0.47 & $74.844 / 5.78$ & $\begin{array}{l}\text { Intermediate filament protein ifa-1, } \\
\text { partial }\end{array}$ \\
\hline & KRX47705.1 & 293 & 4 & 4 & 3 & 0.14 & $150.442 / 6.28$ & Serine protease 30 \\
\hline & KRZ09733.1 & 323 & 5 & 5 & 5 & 0.28 & $96.031 / 6.00$ & $\begin{array}{l}\text { Mitochondrial-processing peptidase } \\
\text { subunit beta, partial }\end{array}$ \\
\hline & KRZ17128.1 & 256 & 4 & 4 & 9 & 0.51 & $46.607 / 5.26$ & Putative histone-binding protein Caf1 \\
\hline & KRY13378.1 & 250 & 5 & 5 & 9 & 0.54 & $54.969 / 5.66$ & Rab GDP dissociation inhibitor alpha \\
\hline
\end{tabular}

\section{${ }^{\mathrm{a}}$ Mascot score}

${ }^{\mathrm{b}}$ Matched peptide

'Sequence

${ }^{\mathrm{d}}$ Sequence coverage (\%)

${ }^{e}$ Exponentially modified protein abundance index

Experimental nominal mass $(\mathrm{kDa})$ and isoelectric point

Table 5 Alphabetical list of stage-specific antigenic proteins of muscle larvae of T. britovi, which reacted with pig sera collected at $10 \mathrm{dpi}$, together with spot number information. Identification by LC-MS/MS

\begin{tabular}{ll}
\hline Protein name & Spot number \\
\hline 26S protease regulatory subunit 7 & 31 \\
Actin-5C & $29 / 30$ \\
Enolase, partial & 30 \\
Hypothetical protein T03_17187 & 30 \\
Protein disulfide-isomerase 2 & 32 \\
Putative Tubulin/FtsZ family, GTPase domain protein & 32 \\
V-type proton ATPase catalytic subunit A & 33 \\
Mitochondrial-processing peptidase subunit beta, partial & 30 \\
Serine protease 30 & 30 \\
\hline
\end{tabular}

and development of Trichinella in the host [10, 26, 28, 51]. The most frequently identified immunodominant antigens of ML T. britovi recognized by infection sera include 14-3-3 protein zeta, actin-5C, ATP synthase subunit d, deoxyribonuclease-2-alpha, poly-cysteine and histide-tailed protein, enolase, V-type proton ATPase catalytic and serine protease 30 . For example, the actin-5c protein (recognized by sera at $10 \mathrm{dpi} / 60$ dpi), known to bind ATP molecules (GO), has previously been identified with the use of early and late infection sera $[26,52]$. This protein is related to the invasion of a parasite into the intestinal epithelial cells and plays a critical role in larval development [53]. Serine protease 30 , with peptidase and hydrolase activities, was recognized by sera at $10 \mathrm{dpi} / 60 \mathrm{dpi}$. The 
Table 6 Alphabetical list stage-specific antigenic proteins of muscle larvae of $T$. britovi, which reacted with pig sera collected at $60 \mathrm{dpi}$, together with spot number information. Identification by LC-MS/MS

\begin{tabular}{|c|c|}
\hline Protein name & Spot number \\
\hline 1,5-anhydro-D-fructose reductase & 26,27 \\
\hline 14-3-3 protein zeta & 20 \\
\hline $40 S$ ribosomal protein SA, partial & 16 \\
\hline Actin-5C & 29,30 \\
\hline ATP synthase subunit $d$, mitochondrial & 6 \\
\hline Calponin -like protein OV9M, partial & 12 \\
\hline Cuticlin-1, partial & 13,14 \\
\hline Deoxyribonuclease-2-alpha & 12 \\
\hline Disorganized muscle protein 1 & 17,19 \\
\hline Glutamine synthetase & 11 \\
\hline $\begin{array}{l}\text { Guanine nucleotide-binding protein } \\
\text { subunit beta-1, partial }\end{array}$ & 17 \\
\hline Hypothetical protein T03_17187 & 30 \\
\hline Hypothetical protein T12_13379, partial & 16,17 \\
\hline $\begin{array}{l}\text { Microtubule-associated protein RP/EB } \\
\text { family member } 3 \text {, partial }\end{array}$ & 17 \\
\hline $\begin{array}{l}\text { Mitochondrial-processing peptidase } \\
\text { subunit beta, partial }\end{array}$ & 30 \\
\hline Poly-cysteine and histidine-tailed protein & 12 \\
\hline $\begin{array}{l}\text { Propionyl-CoA carboxylase alpha chain, } \\
\text { mitochondrial }\end{array}$ & $21,22,23$ \\
\hline $\begin{array}{l}\text { Putative 3-hydroxyacyl-CoA } \\
\text { dehydrogenase }\end{array}$ & 10 \\
\hline Putative histone-binding protein Caf1 & 30 \\
\hline $\begin{array}{l}\text { Pyruvate dehydrogenase E1 } \\
\text { component subunit beta, mitochondrial }\end{array}$ & 18 \\
\hline Rab GDP dissociation inhibitor alpha & 30 \\
\hline Secernin-3 & 25,29 \\
\hline Serine protease 30 & 30 \\
\hline Stromal cell-derived factor 2 & 4 \\
\hline Toll-interacting protein & 20 \\
\hline
\end{tabular}

protein belongs to serine protease family, along with enzymes that take part in digestion, blood coagulation and fibrinolysis processes. It is involved in host tissues and cell invasions, and plays a pivotal role in nematode molting [54]. Additionally, deoxyribonuclease 2-alpha of the deoxyribonuclease II family was identified, which plays an important role in Trichinella invasion, development and survival [55]. The $60 \mathrm{dpi}$ sera also identified the 14-3-3 protein. This is a key regulator of multiple biological processes, including signal transduction, cell differentiation and cell survival, it is also known to induce humoral and cellular immune response and has been tested as a potential vaccine target [56, 57]. The GO analysis revealed that some of the isolated proteins possess catalytic, ligase, hydrolase and peptidase activities, and are responsible for ATP and glutamine synthesis processes; these include ATP-synthase subunit d, glutamine synthase and propionyl-CoA carboxylase alpha chain, all of which were recognized in the $60 \mathrm{dpi}$ sera. GO analysis also showed mitochondrial-processing peptidase (MPP) subunit beta, secernin-3 protein and the previously mentioned serine protease 30 to demonstrate proteolytic and peptidase activity [58]. Microtubuleassociated protein RP/EB family member 3 and cuticlin1 , classified as a cellular component belonging to the ML proteome and recognized by sera at $60 \mathrm{dpi}$, possesses a microtubule binding function. In Caenorhabditis elegans, cuticlin-1 contributes to the formation of extracellular envelopes, thereby protecting the organism from the environment [59].

It is important to note that in accordance with previous studies [11, 60,61], the $10 \mathrm{dpi}$ sera in the present study identified the protein enolase in crude ML extract. Bernal et al. [61] revealed that enolase plays a part in many processes, including fibrinolysis and degradation of the extracellular matrix, through the activation of plasminogen (a proenzyme of the serine protease plasmin). Moreover, this enzyme may contribute to tissue migration during all T. spiralis developmental stages [59]. Dea-Ayuela \& Bolas-Fernandez [30] confirmed that enolase the immunoreactive property using a combination of 2D-immunoblot and MS. Our findings also confirm the presence of a common proteins for both $T$. britovi stages which was recognized by sera from pigs at $10 \mathrm{dpi}$ and $60 \mathrm{dpi}$. One particularly well-studied group of proteins comprises the heat-shock proteins (Hsps), which are known to assist the parasite in tissue invasion and intracellular survival, as well as protect it against injury or stress conditions arising as a result of host immune response stimulation [62]. This is consistent with earlier results which identified Hsps as being a common to the adult and muscle larvae stages [10, 26, 51, 55, 63], and were recognized by sera at $15 \mathrm{dpi}$ and $45 \mathrm{dpi}$ [11]. The present GO analysis demonstrated that the identified Hsp proteins present oxidoreductase and structural molecule activity, and that they are located on ribosomes and take part in the translation processes, suggesting that they participate in host cellular stress and immune responses, as well as in the regulation of gene expression and parasite development [27, 64].

Our findings also indicate that the heat-shock protein beta identified in both the Ad and ML proteomes belongs to the small heat-shock proteins (sHsp), which are considered to be an important focus of research in the fight against parasitic diseases [65]. Wu et al. [66] 
Table 7 Alphabetical list of antigenic proteins, common for both adult worms (Ad) and muscle larvae (ML) stages T. britovi recognized by sera at $60 \mathrm{dpi}$ and $10 \mathrm{dpi}$, together with spot number information. Identification by LC-MS/MS

\begin{tabular}{|c|c|c|c|}
\hline \multirow[t]{2}{*}{ Protein name } & \multirow{2}{*}{$\begin{array}{l}\text { Spot number Ad T. britovi } \\
10 \mathrm{dpi}\end{array}$} & \multicolumn{2}{|c|}{ Spot number ML T. britovi } \\
\hline & & $10 \mathrm{dpi}$ & $60 \mathrm{dpi}$ \\
\hline 32 kDa beta-galactoside-binding lectin lec-3 (Galectin) & 11 & - & 9,10 \\
\hline 32 kDa beta-galactoside-binding lectin, partial (Galectin) & 12,26 & - & 25 \\
\hline Alpha-crystallin B chain & 19 & - & 4 \\
\hline ATP synthase subunit beta, mitochondrial & 27,30 & 32 & - \\
\hline Dedicator of cytokinesis protein 1 & 15 & - & 2 \\
\hline GTP-binding nuclear protein Ran & 25 & - & 6 \\
\hline Heat-shock 70 kDa protein, partial & $6,7,8,27$ & - & 14 \\
\hline Heat-shock protein beta-1 & $15,16,17,18,19$ & - & $1,2,3,4$ \\
\hline Intermediate filament protein B & $6,7,8$ & $24 a, b, c$ & 24 \\
\hline Intermediate filament protein ifa-1, partial & $3,5,6,7,8$ & $24 \mathrm{a} / \mathrm{b} / \mathrm{c}, 30$ & $24,29,30$ \\
\hline OV-16 antigen, partial & 16,17 & - & 3 \\
\hline Peroxiredoxin-2, partial & $14,19,30$ & - & 5,6 \\
\hline Protein MEMO1, partial & 26 & - & 25 \\
\hline Transcription factor BTF3 -like protein 4 & 18 & - & 1 \\
\hline Tropomyosin, partial & 10 & - & $15,19,20,29$ \\
\hline V-type proton ATPase subunit E & 28 & 33 & - \\
\hline
\end{tabular}

reported that sHsp likely play a role in enhancing the survival of the $T$. spiralis muscle larvae under conditions of chemical and physical stress, as well as in the development of larvae. Wang et al. [64] suggested that recombinant $\mathrm{Hsp} 70$ is an immunogenic protein released by parasites and that it is exposed to the host immune system during infection.

Intermediate filament protein (IFA-1) and intermediate filament protein B were identified in both $T$. britovi proteomes. These are members of the diverse family of intermediate filaments; these are cytoskeletal components of animal cells which contribute to their mechanical strength and facilitate growth [67]. In nematodes, they allow epidermal elongation in the larvae, worm growth and muscle stability maintenance [68]. Peroxiredoxin-2 has antioxidant and oxidoreductase activity, participates in cellular oxidant detoxification processes and preserves cell redox homeostasis. It therefore plays a crucial role during the host immune response by protecting parasites from endogenous and host-derived ROS, and is possibly involved in cellular signaling [69].

The present study examined somatic extracts taken from adult worms (AW) and muscle larvae of T. brit$o v i$. Some of the proteins present in these somatic extracts might not be excretory-secretory (E-S) proteins, and they cannot be exposed to the host immune system and induce the specific antibody response. Hence, some of the identified proteins may have less sero- diagnostic value, or perhaps no significance at all. Nevertheless, in the process of Trichinella infection, the E-S antigens produced by the AW and ML are directly exposed to the immune system and elicit the production of specific anti-Trichinella antibodies by the host. Immunoproteomics studies have identified the early diagnostic antigens associated with the E-S proteins of $T$. spiralis AW and ML in animal or patient sera during early infection, and the recombinant 31 $\mathrm{kDa}$ antigen from $T$. spiralis ML E-S proteins has been proved to be valuable for early diagnosis of trichinellosis [70, 71]. Hence, further diagnostic antigens for $T$. britovi infection may be identified by future studies on the E-S antigens of AD and ML with early infection sera.

Few proteomic studies examine T. britovi exclusively or compare the findings with those of different Trichinella spp. [9], and those that have been performed focus on the characterization of mitochondrial genomes [72]. This approach results in the acquisition of a narrow range of knowledge regarding the nuclear genomic or transcriptomic data associated with this parasite, and this narrow focus presents a serious obstacle in the identification of its proteins, and the understanding of their precise function during parasite invasion. Therefore, many proteins are not represented in existing studies, and their precise function can only be assumed on the basis of indirect resemblance analysis. 


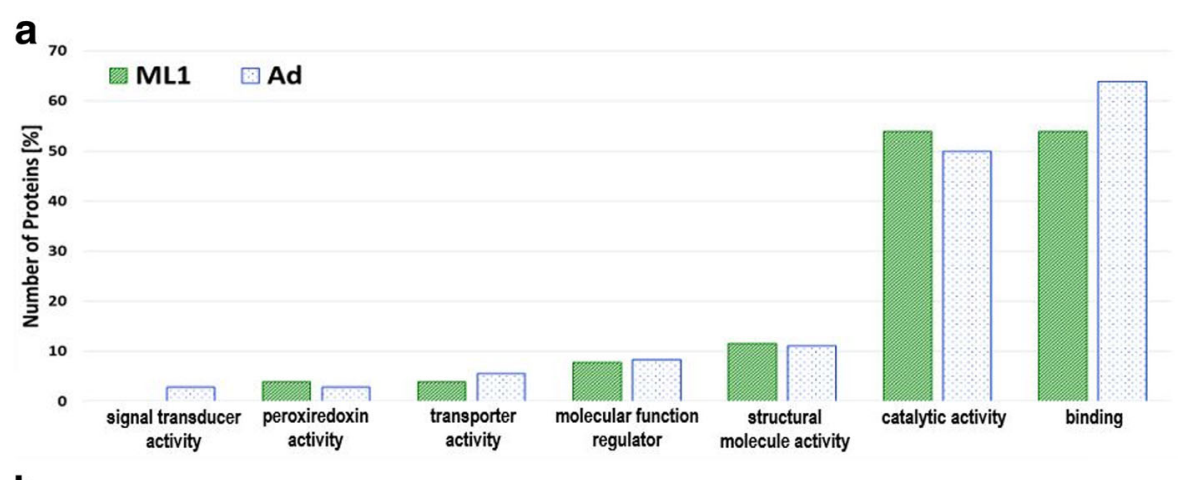

b

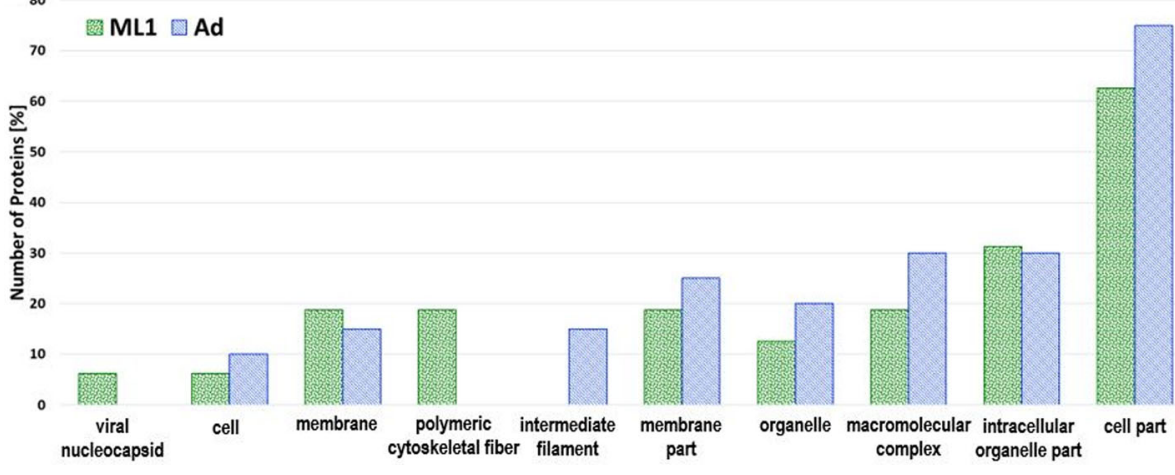

C

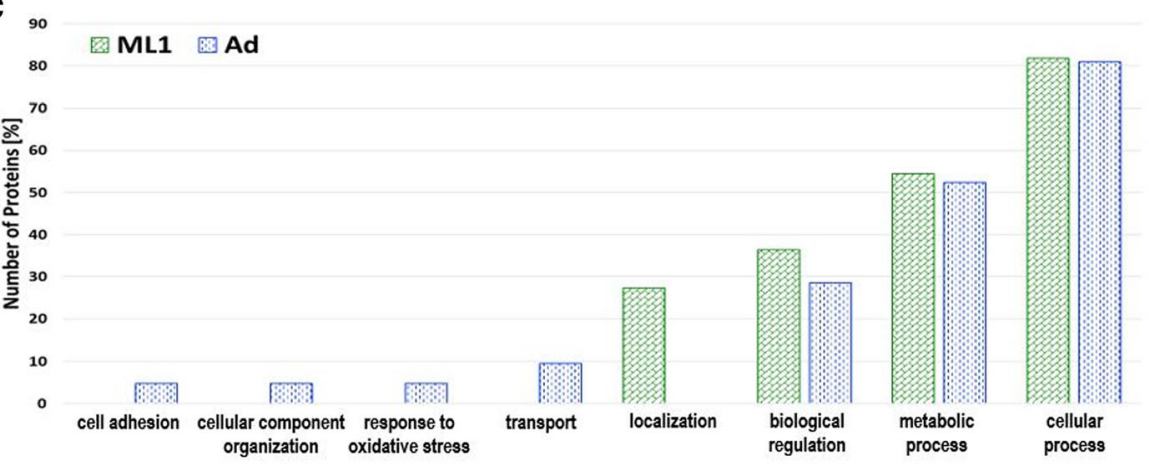

Fig. 3 Comparison of Gene Ontology (GO) database analysis outcomes for T. britovi muscle (ML) and adult (Ad) larvae identified proteins. The proteins were categorized according to molecular function (a), cellular component (b) and biological process (c)

\section{Conclusions}

To our knowledge, the present study describes the first immunoproteomic identification of the antigenic proteins of adult worm and muscle larvae of T. britovi. The somatic extracts from adult worms and muscle larvae of $T$. britovi were specifically recognized by $T$. britovi-infected pig sera at $10 \mathrm{dpi}$ and $60 \mathrm{dpi}$; a total of 70 prominent protein spots were thus identified, and these were found to contain 45 adult worm and 52 muscle larvae proteins. Adult worms and muscle larvae of $T$. britovi produce proteins (both stage-specific and common proteins) with antigenic properties, some of which have been identified in other helminths as potential diagnostic targets and vaccine candidates. The presence of common and stage-specific proteins for both investigated T. britovi stages was confirmed; these included heat-shock proteins, intermediate filament protein IFA-1, $32 \mathrm{kDa}$ beta-galactosidase-binding lectin, peroxiredoxin-2 or 14-3-3 protein, actin-5C, paramyosin, intermediate filament protein $\mathrm{B}$, calreticulin, deoxyribonuclease-2-alpha, enolase, serine protease. These proteins were related to many significant molecular functions, cellular components and biological processes of the parasite, suggesting that the somatic proteins of these two developmental stages may induce a humoral immune response, making them potential antigens for the development of diagnostic methods for $T$. britovi infection. 


\section{Abbreviations}

2-DE: Two-dimensional electrophoresis; Ad: Adult worms; dpi: Days postinfection; ELISA: Enzyme-linked immunosorbent assay; ES: Excretory-secretory; IEF: Isoelectric focusing; LC-MS/MS: Liquid chromatography-tandem mass spectrometry; ML: Muscle larvae; MW: Molecular weight; NBL: Newborn larvae; pl: Isoelectric point; PVDF: Polyvinylidene fluoride membrane

\section{Acknowledgements}

We are grateful to K. Nöckler (Federal Institute for Risk Assessment, Berlin, Germany) for providing experimentally Trichinella-infected sera.

\section{Funding}

Financial support for this study was provided by the National Science Centre Poland (grant UMO-2015/18/E/NZ6/00502).

\section{Availability of data and materials}

The data supporting the conclusions of this article are included within the article. The datasets generated during the present study have been deposited in the ProteomeXchange Consortium repository under the accession number PXD011215.

\section{Authors' contributions}

$J B$ designed and supervised the experiments. JB and SG performed the experiments, analyzed the data and drafted the manuscript. BM contributed in the data analysis and manuscript preparation. All authors read and approved the final manuscript.

\section{Ethics approval and consent to participate}

All experimental procedures used in the present study had been pre-approved by the First Local Ethical Committee for Scientific Experiments on Animals in Warsaw, Poland (resolution no.: 020/2016, 23 March 2016).

\section{Consent for publication}

Not applicable.

\section{Competing interests}

The authors declare that they have no competing interests.

\section{Publisher's Note}

Springer Nature remains neutral with regard to jurisdictional claims in published maps and institutional affiliations.

Received: 27 July 2018 Accepted: 28 October 2018

Published online: 12 November 2018

\section{References}

1. Pozio E. The opportunistic nature of Trichinella - exploitation of new geographies and habitats. Vet Parasitol. 2013;194:128-32.

2. Pozio E. World distribution of Trichinella spp. infections in animals and humans. Vet Parasitol. 2007;149:3-21.

3. Rostami A, Gamble HR, Dupouy-Camet J, Khazan H, Bruschi F. Meat sources of infection for outbreaks of human trichinellosis. Food Microbiol. 2017:64:65-71.

4. Gottstein B, Pozio E, Nöckler K. Epidemiology, diagnosis, treatment, and control of trichinellosis. Clin Microbiol Rev. 2009;22:127-45.

5. Ortega-Pierres G, Vaquero-Vera A, Fonseca-Liñán R, Bermúdez-Cruz RM Argüello-García R. Induction of protection in murine experimental models against Trichinella spiralis: an up-to-date review. J Helminthol. 2015;89:526-39.

6. Philipp M, Parkhouse RM, Ogilvie BM. Changing proteins on the surface of a parasitic nematode. Nature. 1980;287:538-40.

7. Bioreau P, Vayssier M, Fabien JF, Perret C, Calamel M, Soulé C. Characterization of eleven antigenic groups in Trichinella genus and identification of stage and species markers. Parasitology. 1997;115:641-51.

8. Takahashi Y. Antigens of Trichinella spiralis. Parasitol Today. 1997;13:104-6.

9. Bień J, Nareaho A, Varmanen P, Goździk K, Moskwa B, Cabaj W, et al. Comparative analysis of excretory-secretory antigens of Trichinella spiralis and Trichinella britovi muscle larvae by two-dimensional difference ge electrophoresis and immunoblotting. Proteome Sci. 2012;10:10.
10. Bień J, Cabaj W, Moskwa B. Recognition of antigens of three different stages of the Trichinella spiralis by antibodies from pigs infected with T. spiralis. Exp Parasitol. 2013;134:129-37.

11. Bień J, Cabaj W, Moskwa B. Proteomic analysis of potential immunoreactive proteins from muscle larvae and adult worms of Trichinella spiralis in experimentally infected pigs. Folia Parasitol. 2015;62:022.

12. Tang B, Liu M, Wang L, Yu S, Shi H, Boirea $P$, et al. Characterisation of a high-frequency gene encoding a strongly antigenic cystatin-like protein from Trichinella spiralis at its early invasion stage. Parasit Vectors. 2015;8:78.

13. Sun GG, Song $Y Y$, Jiang $P$, Ren HN, Yan SW, Han $Y$, et al. Characterization of Trichinella spiralis putative serine protease. Study of its potential as serodiagnostic tool. PLoS Negl Trop Dis. 2018;12:e0006485.

14. Zhang Y, Wang Z, Li L, Cui J. Molecular characterization of Trichinella spiralis aminopeptidase and its potential as a novel vaccine candidate antigen against trichinellosis in BALB/c mice. Parasit Vectors. 2013:6:246.

15. Yang W, Li LG, Liu RD, Sun GG, Liu CY, Zhang SB, et al. Molecular identification and characterization of Trichinella spiralis proteasome subunit beta type-7. Parasit Vectors. 2015;8:18

16. Sun GG, Ren HN, Liu RD, Song YY, Qi X, Hu CX, et al. Molecular characterization of a putative serine protease from Trichinella spiralis and its elicitedimmune protection. Vet Res. 2018:49:59.

17. Song $Y Y$, Zhang $Y$, Yang D, Ren HN, Sun GG, Jiang P, et al. The immune protection induced by a serine protease inhibitor from the foodborne parasite Tricinella spiralis. Front Microbiol. 2018;9:1544

18. Näreaho A, Ravanko K, Hölttä E, Sukura A. Comparative analysis of Trichinella spiralis and Trichinella nativa proteins by two-dimensional gel electrophoresis. Parasitol Res. 2006;98:349-54.

19. Robinson MW, Greig R, Beattie KA, Lamont DJ, Connolly B. Comparative analysis of the excretory-secretory proteome of the muscle larva of Trichinella pseudospiralis and Trichinella spiralis. Int J Parasitol. 2007:37:139-48.

20. Liu P, Wu XP, Bai X, Wang XL, Yu L, Rosenthal B, et al. Screening of early antigen genes of adult-stage Trichinella spiralis using pig serum from different stages of early infection. Vet Parasitol. 2013;194:222-5.

21. Somboonpatarakun C, Rodpai R, Intapan PM, Sanpool O, Sadaow L, Wongkham C, et al. Immuno-proteomic analysis of Trichinella spiralis, T. pseudospiralis, and T. papuae extracts recognized by human T. spiralisinfected sera. Parasitol Res. 2018;117:201-12.

22. Wang J, Zhao F, Yu CX, Xiao D, Song LJ, Yin XR, et al. Identification of proteins inducing short-lived antibody responses from excreted/secretory products of Schistosoma japonicum adult worms by immunoproteomic analysis. J Proteomics. 2013;87:53-67.

23. Sun XM, Ji YS, Elashram SA, Lu ZM, Liu XY, Suo $X$, et al. Identification of antigenic proteins of Toxoplasma gondii $\mathrm{RH}$ strain recognized by human immunoglobulin G using immunoproteomics. J Proteomics. 2012:77:423-32

24. Acevedo N, Mohr J, Zakzuk J, Samonig M, Briza P, Erler A, et al. Proteomic and immunochemical characterization of glutathione transferase as a new allergen of the nematode Ascaris lumbricoides. PLoS One. 2013;8:e78353.

25. Santivanez SJ, Hernandez-Gonzalez A, Chile N, Oleaga A, Arana Y, Palma S, et al. Proteomic study of activated Taenia solium oncospheres. Mol Biochem Parasitol. 2010:171:32-9.

26. Yang J, Pan W, Sun X, Zhao X, Yuan G, Sun Q, et al. Immunoproteomic profile of Trichinella spiralis adult worm proteins recognized by early infection sera. Parasit Vectors. 2015:8:20.

27. Bermúdez-Cruz RM, Fonseca-Liñán R, Grijalva-Contreras LE, MendozaHernández G, Ortega-Pierres MG. Proteomic analysis of antigens from early developmental stages of Trichinella spiralis. Vet Parasitol. 2016;231:22-31.

28. Cui J, Liu RD, Wang L, Zhang X, Jiang P, Liu MY, et al. Proteomic analysis of surface proteins of Trichinella spiralis muscle larvae by two-dimensional gel electrophoresis and mass spectrometry. Parasit Vectors. 2013;6:355.

29. Robinson MW, Connolly B. Proteomic analysis of the excretory-secretory proteins of the Trichinella spiralis L1 larva, a nematode parasite of skeletal muscle. Proteomics. 2005;5:4525-32.

30. Dea-Ayuela MA, Bolas-Fernandez F. Two-dimensional electrophoresis and mass spectrometry for the identification of species-specific Trichinella antigens. Vet Parasitol. 2005:132:43-9.

31. Pozio E, Cossu P, Marucci G, Amati M, Ludovisi A, Morales MA, et al. The birth of a Trichinella britovi focus on the Mediterranean island of Sardinia (Italy). Vet Parasitol. 2009;159:361-3.

32. Fichi G, Stefanelli S, Pagani A, Luchi S, De Gennaro M, Gómez-Morales MA, et al. Trichinellosis outbreak caused by meat from a wild boar hunted in an 
Italian region considered to be at negligible risk for Trichinella. Zoonoses Public Health. 2015;62:285-91.

33. Akkoc N, Kuruuzum Z, Akar S, Yuce A, Onen F, Yapar N, et al. A large-scale outbreak of trichinellosis caused by Trichinella britovi in Turkey. Zoonoses Public Health. 2009;56:65-70.

34. Gomez-Garcia V, Hernandez-Quero J, Rodriguez-Osorio M. Short report: Human infection with Trichinella britovi in Granada. Spain. Am J Trop Med Hyg. 2003;68:463-4.

35. Messiaen P, Forier A, Vanderschueren S, Theunissen C, Nijs J, Van Esbroeck $M$, et al. Outbreak of trichinellosis related to eating imported wild boar meat, Belgium, 2014. Euro Surveill. 2016;21. https://doi.org/10.2807/15607917.ES.2016.21.37.30341.

36. Pozio E, Varese P, Morales MA, Croppo GP, Pelliccia D, Bruschi F. Comparison of human trichinellosis caused by Trichinella spiralis and by Trichinella britovi. Am J Trop Med Hyg. 1993:48:568-75.

37. Kapel CM, Gamble HR. Infectivity, persistence, and antibody response to domestic and sylvatic Trichinella spp. in experimentally infected pigs. Int 」 Parasitol. 2000;30:215-21.

38. Romano F, Motta A, Melino M, Negro M, Gavotto G, Decasteli L, et al. Investigation on a focus of human trichinellosis revealed by an atypical clinical case: after wild-boar (Sus scrofa) pork consumption in northern Italy. Parasite. 2011;18:85-7.

39. Nunez GG, Costantino SN, Venturiello SM. Detection of coproantibodies and faecal immune complexes in human trichinellosis. Parasitology. 2007:134:723-7.

40. Wang L, Cui J, Hu DD, Liu RD, Wang ZQ. Identyfication of early diagnostic antigens from major excretory-secretory proteins of Trichinella spiralis muscle larvae using immunoproteomics. Parasit Vectors. 2014;7:40.

41. Zocevic A, Mace P, Vallee I, Blaga R, Liu M, Lacour SA, et al. Identification of Trichinella spiralis early antigens at the pre-adult and adult stages. Parasitology. 2011;138:463-71.

42. Gounaris K. Nucleotidase cascades are catalyzed by secreted proteins of the parasitic nematode Trichinella spiralis. Infect Immun. 2002;70:4917-24.

43. Sulima A, Bień J, Savijoki K, Näreaho A, Sałamatin R, Conn DB, et al. Identification of immunogenic proteins of the cysticercoid of Hymenolepis diminuta. Parasit Vectors. 2017:10:577.

44. Sun R, Zhao X, Wang Z, Yang J, Zhao L, Zhan B, et al. Trichinella spiralis paramyosin binds human complement $\mathrm{C} 1 \mathrm{q}$ and inhibits classical complement activation. PLoS Negl Trop Dis. 2015;9:e0004310.

45. Wang $Y$, Bai $X$, Zhu H, Wang $X$, Shi H, Tang B, et al. Immunoproteomic analysis of the excretory-secretory products of Trichinella pseudospiralis adult worms and newborn larvae. Parasit Vectors. 2017;10:579.

46. Gunning PW, Ghoshdastider U, Whitaker S, Popp D, Robinson RC. The evolution of compositionally and functionally distinct actin filaments. J Cell Sci. 2015;128:2009-19.

47. Zhao L, Shao S, Chen Y, Sun X, Sun R, Huang J, et al. Trichinella spiralis calreticulin binds human complement $\mathrm{Clq}$ as an immune evasion strategy. Front Immunol. 2017:8:636.

48. Zhang Z, Yang J, Wei J, Yang $Y$, Chen $X$, Zhao $X$, et al. Trichinella spiralis paramyosin binds to $C 8$ and $C 9$ and protects the tissue-dwelling nematode from being attacked by host complement. PLoS Negl Trop Dis. 2011;5:e1225.

49. Knight AJ, Behm CA. Minireview: the role of the vacuolar ATPase in nematodes. Exp Parasitol. 2012;132:47-55.

50. Rosa BA, Townsend R, Jasmer DP, Mitreva M. Functional and phylogenetic characterization of proteins detected in various nematode intestinal compartments. Mol Cell Proteomics. 2015;14:812-27.

51. Liu RD, Cui J, Liu XL, Jiang P, Sun GG, Zhang X, et al. Comparative proteomic analysis of surface proteins of Trichinella spiralis muscle larvae and intestinal infective larvae. Acta Trop. 2015;150:79-86.

52. Wang ZQ, Wang L, Cui J. Proteomic analysis of Trichinella spiralis proteins in intestinal epithelial cells after culture with their larvae by shotgun LC-MS/ MS approach. J Proteom. 2012;75:2375-83.

53. MacQueen AJ, Baggett JJ, Perumov N, Bauer RA, Januszewski T, Schriefer L, et al. ACT-5 is an essential Caenorhabditis elegans actin required for intestinal microvilli formation. Mol Biol Cell. 2005;16:3247-59.

54. Dzik JM. Molecules released by helminth parasites involved in hosts colonization. Acta Biochim Pol. 2006;53:33-64.

55. Liao C, Liu M, Bai X, Liu P, Wang X, Li T, et al. Characterisation of a plancitoxin-1-like DNase II gene in Trichinella spiralis. PLoS Negl Trop Dis. 2014;:8:e3097.
56. Luo QL, Qiao ZP, Zhou YD, Li XY, Zhong ZR, Yu YJ, et al. Application of signaling protein 14-3-3 and $26 \mathrm{kDa}$ glutathione-S-transferase to serological diagnosis of Schistosomiasis japonica. Acta Trop. 2009;112:91-6.

57. Yang J, Zhu W, Huang J, Wang X, Sun X, Zhan B, et al. Partially protective immunity induced by the 14-3-3 protein from Trichinella spiralis. Vet Parasitol. 2016;231:63-8.

58. Nomura H, Athauda SB, Wada H, Maruyama Y, Takahashi K, Inoue H. Identification and reverse genetic analysis of mitochondrial processing peptidase and the core protein of the cytochrome bc1 complex of Caenorhabditis elegans, a model parasitic nematode. J Biochem. 2006; 139:967-79.

59. Sapio MR, Hilliard MA, Cermola M, Favre R, Bazzicalupo P. The Zona Pellucida domain containing proteins, CUT-1, CUT-3 and CUT-5, play essential roles in the development of the larval alae in Caenorhabditis elegans. Dev Biol. 2005;282:231-45.

60. Nakada T, Nagano I, Wu Z, Takahashi Y. Molecular cloning and functional expression of enolase from Trichinella spiralis. Parasitol Res. 2005;96:354-60.

61. Bernal D, de la Rubia JE, Carrasco-Abad AM, Toledo R, Mas-Coma S, Marcilla A. Identification of enolase as a plasminogen-binding protein in excretorysecretory products of Fasciola hepatica. FEBS Lett. 2004;563:203-6.

62. Nagano I, Wu Z, Takahashi Y. Functional genes and proteins of Trichinella spp. Parasitol Res. 2009;104:197-207.

63. Ko RC, Fan L. Heat shock response of Trichinella spiralis and T. pseudospiralis. Parasitology. 1996;96:89-95.

64. Wang S, Zhu X, Yang Y, Yang J, Gu Y, Wei J, et al. Molecular cloning and characterization of heat shock protein 70 from Trichinella spiralis. Acta Trop. 2009;110:46-51

65. Pérez-Morales D, Espinoza B. The role of small heat shock proteins in parasites. Cell Stress Chaperones. 2015;20:767-80.

66. Wu Z, Nagano I, Boonmars T, Takahashi Y. Thermally induced and developmentally regulated expression of a small heat shock protein in Trichinella spiralis. Parasitol Res. 2007;101:201-12.

67. Wang N, Stamenović D. Contribution of intermediate filaments to cell stiffness, stiffening, and growth. Am J Physiol Cell Physiol. 2000;279:C188-94.

68. Woo WM, Goncharov A, Jin Y, Chisholm A. Intermediate filaments are required for C. elegans epidermal elongation. Dev Biol. 2004;267:216-29.

69. Gretes MC, Poole LB, Karplus PA. Peroxiredoxins in parasites. Antioxid Redox Signal. 2012;17:608-33.

70. Wang L, Wang ZQ, Hu DD, Cui J. Proteomic analysis of Trichinella spiralis muscle larvae excretory-secretory proteins recognized by early infection sera. Biomed Res Int. 2013;2013:139745.

71. Wang ZQ, Liu RD, Sun GG, Song YY, Jiang P, Zhang X, et al. Proteomic analysis of Trichinella spiralis adult worm excretory-secretory proteins recognized by sera of patients with early trichinellosis. Front Microbiol. 2017;8:986.

72. Mohandas N, Pozio E, La Rosa G, Korhonen PK, Young ND, Koehler AV, et al. Mitochondrial genomes of Trichinella species and genotypes - a basis for diagnosis, and systematic and epidemiological explorations. Int J Parasitol. 2014;44:1073-80.

\section{Ready to submit your research? Choose BMC and benefit from:}

- fast, convenient online submission

- thorough peer review by experienced researchers in your field

- rapid publication on acceptance

- support for research data, including large and complex data types

- gold Open Access which fosters wider collaboration and increased citations

- maximum visibility for your research: over $100 \mathrm{M}$ website views per year

At BMC, research is always in progress.

Learn more biomedcentral.com/submissions 